\title{
DO DISCRETE CHOICE APPROACHES TO VALUING URBAN AMENITIES YIELD DIFFERENT RESULTS THAN HEDONIC MODELS?
}

\author{
Paramita Sinha \\ Martha L. Caulkins \\ Maureen L. Cropper \\ Working Paper 24290 \\ http://www.nber.org/papers/w24290 \\ NATIONAL BUREAU OF ECONOMIC RESEARCH \\ 1050 Massachusetts Avenue \\ Cambridge, MA 02138 \\ February 2018, Revised September 2019
}

We thank the US Environmental Protection Agency for funding. This paper would not have been possible without GIS support from RTI. We thank David Albouy, Nick Kuminoff and Chris Timmins, for their comments. Ingmar Prucha and Hao Bo provided valuable help with model estimation. Any errors are ours. The views expressed herein are those of the authors and do not necessarily reflect the views of the National Bureau of Economic Research.

NBER working papers are circulated for discussion and comment purposes. They have not been peer-reviewed or been subject to the review by the NBER Board of Directors that accompanies official NBER publications.

(C) 2018 by Paramita Sinha, Martha L. Caulkins, and Maureen L. Cropper. All rights reserved. Short sections of text, not to exceed two paragraphs, may be quoted without explicit permission provided that full credit, including $(\odot$ notice, is given to the source. 
Do Discrete Choice Approaches to Valuing Urban Amenities Yield Different Results Than Hedonic Models?

Paramita Sinha, Martha L. Caulkins, and Maureen L. Cropper

NBER Working Paper No. 24290

February 2018, Revised September 2019

JEL No. Q51,Q54

\section{ABSTRACT}

Amenities that vary across cities are typically valued using either a hedonic model, in which amenities are capitalized into wages and housing prices, or a discrete model of household location choice. In this paper, we use the 2000 Public Use Microdata Sample (PUMS) to value climate amenities using both methods. We compare estimates of marginal willingness to pay (MWTP), allowing preferences for climate amenities to vary by location. We find that mean MWTP for warmer winters is about twice as large using the discrete choice approach as with the hedonic approach; mean MWTP for cooler summers is approximately the same. The two approaches differ, however, in their estimates of taste sorting. The discrete choice model implies that households with the highest MWTP for warmer winters locate in cities with the mildest winters, while the hedonic model does not. Differences in estimates are due to primarily to two factors: (1) the discrete choice model incorporates the psychological costs of moving from one's birthplace, which the hedonic models do not; (2) the discrete choice model uses information on market shares (i.e., population) in estimating parameters, which the hedonic model does not.

Paramita Sinha

Research Triangle Institute

701 13th Street, NW

Suite 750

Washington, DC 20005-3967

psinha@rti.org

Martha L. Caulkins

University of Maryland

caulkins@econ.umd.edu
Maureen L. Cropper

Department of Economics

University of Maryland

College Park, MD 20742

and NBER

cropper@econ.umd.edu 


\section{Introduction}

To value amenities that vary across cities, researchers have typically followed one of two approaches. They have used either hedonic models of wages and housing prices (Roback 1982; Blomquist et al. 1988; Albouy et al. 2016) or discrete models of location choice (Cragg and Kahn 1997; Bayer et al. 2009; Fan et al. 2016; Sinha et al. 2018b). The former approach infers willingness to pay for amenities by estimating hedonic price functions for wages and housing costs as a function of location-specific attributes; the second, by estimating the probability that consumers choose a city in which to live as a function of wages, housing prices, and locationspecific attributes.

Cragg and Kahn (1997), Bayer et al. (2009), and Sinha et al. (2018b) note that the discrete choice approach typically produces estimates of amenity values that are very different from estimates produced by the continuous hedonic approach. In a discrete choice model where households choose the US state in which to reside, Cragg and Kahn (1997) find the marginal willingness to pay for July and February temperatures exceeds the marginal prices implied by hedonic price functions. Bayer et al. (2009) estimate marginal willingness to pay (MWTP) to reduce air pollution using a discrete choice approach and find MWTP is three times greater than values capitalized into per capita incomes and property values. Sinha et al.'s (2018b) discrete choice model estimates higher damages associated with projected climate changes in US cities under the A2 scenario in the Special Report on Emissions Scenarios than comparable estimates from Albouy et al.'s (2016) hedonic model.

While much previous research has compared the hedonic and discrete choice approaches in the context of a single housing market (Bayer et al. 2007; Klaiber and Phaneuf 2009, Wong forthcoming), valuing amenities that vary across cities introduces different issues. Hedonic estimates of the value of city-specific amenities involve the capitalization of amenities in both the labor and housing markets. An important question is whether these markets should be treated as national markets or city-specific markets. Moving costs across cities are one reason to question the assumption of national labor and housing markets. And moving costs may prevent city-specific amenities from being fully capitalized in wages and housing prices. Hedonic models typically assume perfect mobility, while moving costs are more easily incorporated into discrete choice models.

In this paper, we use the same dataset to value climate amenities—specifically, winter and summer temperature-using hedonic and discrete choice methods. We compare estimates from each approach, allowing preferences for climate amenities to vary by location. Similar to Albouy (2012), our hedonic models regress the weighted sum of wage and housing price indices 
on climate amenities and various city characteristics using metropolitan statistical areas (MSAs) as the geographic unit. Wage and housing price indices are estimated, following Albouy et al. (2016), assuming national labor and housing markets. We construct a weighted sum of wage and housing price indices for each MSA using the same weights as in Albouy et al. (2016) and, alternately, using a traditional set of weights (Roback 1982). We capture preference heterogeneity by allowing the marginal price of climate amenities to vary by city using local linear regressions, in the spirit of Bajari and Benkard (2005) and Bajari and Kahn (2005).

In discrete location choice models, consumers choose among MSAs based on predicted wages and housing costs, moving costs from birthplace, and the same set of location-specific amenities as used in the hedonic models. To capture heterogeneity in preferences, we estimate random parameter logit models and calculate the distribution of each household's tastes for climate conditional on the city in which they live. This allows us to estimate mean MWTP for climate amenities by city.

We focus on prime-aged households when comparing the two approaches. Because the hedonic approach assumes that amenities are capitalized into wages, and because a significant fraction of older households have no wage income, Albouy et al. (2016) focus on workers aged 25-55. We have estimated discrete location choice models for various age groups (Sinha et al. 2018b) and find that preferences for climate amenities vary by the age of the household head; however, we focus on households with heads between 25 and 55 when comparing discrete choice with hedonic estimates.

We find that the two approaches produce different estimates of mean MWTP for winter and summer temperature and different sorting patterns when we allow preferences to vary across cities. Although both approaches find that households have positive MWTP for warmer winters and cooler summers, mean estimates of MWTP for winter temperature produced by the discrete choice approach are about twice as large as estimates produced by the hedonic approach. Moreover, the taste sorting patterns produced by the two approaches are very different. The discrete choice model finds that households sort across locations based on their preferences for winter temperature: there is a strong positive correlation between winter temperature and MWTP for warmer winters. The hedonic model finds a negative correlation between MWTP for warmer winters and winter temperature. The discrete choice model thus projects that under most climate scenarios, the parts of the country that will benefit from warmer winters value this less than the average US household. The hedonic model with adjusted (Albouy) weights projects the opposite.

We also explore why estimates produced by the two approaches vary. One reason is that the hedonic and discrete choice models differ in their underlying assumptions about consumer 
mobility. The hedonic approach assumes perfect mobility, whereas moving costs are more easily incorporated in discrete models of location choice. As Bayer et al. (2009) note, moving costsboth psychological and out-of-pocket-may prevent amenities from being fully capitalized into wages and housing values. When we estimate the discrete choice model without moving costs, the value of climate amenities falls significantly. It is also the case that moving costs, which vary by household and city, help identify sorting patterns in the discrete choice model (Berry and Haile 2010). When they are removed, sorting patterns are (incorrectly) reversed.

A related reason for differences in the two sets of estimates is the way in which data on wages and housing prices are used. The hedonic model assumes a single national labor market and a single housing market. The data are used to estimate price indices for each MSA, assuming that the returns to human capital and marginal prices of housing characteristics are the same everywhere. The discrete choice model assumes that each MSA constitutes a separate labor and a separate housing market. It is the variation in wage income and housing costs across MSAs, as well as the variation in moving costs across MSAs, that identifies household preferences in the discrete choice model. This suggests that differences in how the two models use information on housing and labor markets may account in part for the difference in estimates.

The paper is organized as follows. Section 2 describes the hedonic model of amenity valuation as originally developed by Roback (1982) and modified by Albouy (2012) and Albouy et al. (2016). We present the discrete location choice model that we estimate in section 3 and describe our data and empirical specifications in section 4. Section 5 presents the results of both modeling approaches. Section 6 concludes.

\section{Hedonic Models of Amenity Valuation}

\subsection{The Roback and Albouy Models}

The hedonic approach to valuing location-specific amenities dates from Jennifer Roback’s (1982) seminal article “Wages, Rents, and the Quality of Life,” which built on Rosen’s (1974) model of product differentiation and implicit prices. Roback posited that in a world of perfectly mobile individuals, wages and land prices would adjust to equalize utility in all locations. Consider a world of homogeneous individuals who receive utility from housing, $H$, a traded good, $C$, and a location-specific amenity, $a{ }^{1}{ }^{1}$ In each location, $j$, the individual selects $C$ and $H$ to maximize utility subject to a budget constraint,

\footnotetext{
${ }^{1}$ Roback's model deals with land, not housing. In the subsequent literature, $r$ is treated as the rental rate on housing.
} 


$$
\max _{C_{j}, H_{j}} U\left(C_{j}, H_{j} ; a_{j}\right) \text { s.t. } W_{j}+I=r_{j} H_{j}+C_{j}
$$

where $r_{j}$ is the rental price of housing; $W_{j}$ is wage income; $I$ is nonwage income, which is independent of location; and the price of the traded good, $C$, has been normalized to 1 . $^{2}$ This yields an indirect utility function, $V\left(W_{j}, r_{j}, a_{j}\right)$. If individuals are perfectly mobile, locational equilibrium requires that utility be everywhere equal,

$$
V\left(W_{j}, r_{j}, a_{j}\right)=k
$$

implying that housing prices and wages will adjust to equalize utility. Roback shows that the value to consumers of a small change in $a_{j}$ is given by

$$
\operatorname{MWTP}_{a} \equiv \frac{V_{a}}{V_{W}}=H \frac{d r}{d a}-\frac{d W}{d a} \text { and } \frac{M W T P_{a}}{W} \equiv \frac{V_{a}}{V_{W}} \frac{1}{W}=s_{H} \frac{d \log r}{d a}-\frac{d \log W}{d a}
$$

where $s_{H}$ is the share of the consumer's budget spent on housing.

The literature following Roback (1982) has inferred MWTP for local amenities by estimating hedonic wage and property value equations. For example, Blomquist et al. (1988) use census data on individuals residing in different counties to estimate hourly wage $(w)$ and housing expenditure $(P)$ equations. A common econometric specification in the literature (Gyourko and Tracy 1991) is the semilog 3

$$
\begin{gathered}
\ln w_{m j}=\gamma^{0}+\boldsymbol{X}_{m j}^{w} \boldsymbol{\Gamma}^{X, 0}+\boldsymbol{A}_{j} \Gamma^{A, 0}+v_{m j}^{0} \\
\ln P_{i j}=\delta^{0}+\boldsymbol{X}_{i j}^{P} \boldsymbol{\Delta}^{X, 0}+\boldsymbol{A}_{j} \boldsymbol{\Delta}^{A, 0}+\eta_{i j}^{0}
\end{gathered}
$$

where $w_{m j}$ is the hourly wage earned by worker $m$ in location $j ; \boldsymbol{X}_{m j}^{w}$ is a vector measuring the education, experience, demographic characteristics, industry, and occupation of worker $m$; $P_{i j}$ is housing expenditure by household $i$ in location $j$; and $\boldsymbol{X}_{i j}^{P}$ is a vector of dwelling characteristics. $\boldsymbol{A}_{j}$ is a vector of attributes characterizing location $j$. In using equations (4) and (5) to infer the value of location-specific amenities, Blomquist et al. (1988) multiply the hourly wage by the average number of workers per household and the average number of hours worked per year, and monthly housing expenditure by 12. The two are added together to determine the impact of amenities; thus, implicitly, wage differentials across counties are weighted approximately three times as much as housing price differentials.

\footnotetext{
2 It is assumed that each individual offers a single unit of labor in each location.

3 Blomquist et al. (1988) use Box-Cox transformations of wages and housing prices, i.e., $\left(\mathrm{w}^{\lambda}-1\right) / \lambda$ and $\left(\mathrm{P}^{\lambda}-1\right) / \lambda$. They estimate a value of $\lambda=0.2$ for the housing price equation and $\lambda=0.1$ for the wage equation, in contrast to a logarithmic specification $(\lambda=0)$.
} 
Albouy (2012) makes significant modifications to Roback’s approach. He argues that the weight placed on wage income is too high, relative to the cost of nontraded goods, and he suggests an alternate approach to estimating the value of local amenities. Nontraded goods, as Albouy points out, include more than housing and hence occupy a larger fraction of the household's budget. At the same time, it is after-tax income that matters. This raises the weight placed on nontraded goods (proxied by housing) relative to wages. Second, Albouy estimates wage and housing price indices for each geographic area and combines them into a quality of life (QOL) index, using his adjusted weights. The QOL index is then regressed on site-specific amenities to estimate marginal amenity values.

To elaborate, consider the utility maximization problem faced by households, where indirect utility depends on income (both wage and nonwage), the prices of nontraded goods, taxes, and the location-specific amenities in each location. The MWTP for amenity $a$ as a percentage of average total income $(\bar{m})$ can be shown to be equal to the derivative of a QOL index, as described by equation (6),

$$
\frac{M W T P_{a}}{\bar{m}} \equiv \frac{\partial Q O L_{j}}{\partial a}=\left(s_{H}+\gamma s_{O}\right) \frac{d \ln \left(p_{j, H}\right)}{d a}-(1-\tau) s_{w} \frac{d \ln \left(w_{j}\right)}{d a}
$$

where $s_{H}$ is the share of income spent on housing, $s_{O}$ is the share of income spent on other nontraded goods, $s_{w}$ is the share of income that comes from wages, and $\tau$ is the marginal tax rate. $\gamma$ is the ratio of the housing price to the price of nontraded goods. The QOL index corresponding to (6) can be viewed as the consumption a household is willing to forgo to live in city $j$ compared with living in the average city. The weights in the QOL, however, differ from those in Roback. The weight on housing prices now includes the share of income spent on all local goods, and the weight on wage income has been reduced by taxes. ${ }^{4}$

To estimate QOL indices, Albouy et al. (2016) estimate national wage and housing price equations similar to (4) and (5) in two stages. Including location-specific fixed effects in the hourly wage and housing rent equations in the first stage yields wage and housing price indices, $\lambda_{j}^{w}$ and $\lambda_{j}^{P} \cdot^{5}$

$$
\begin{gathered}
\ln w_{m j}=\boldsymbol{X}_{m j}^{w} \Gamma^{X, 1}+\lambda_{j}^{w}+v_{m j}^{1} \\
\ln P_{i j}=\boldsymbol{X}_{i j}^{P} \Delta^{X, 1}+\lambda_{j}^{P}+\eta_{i j}^{1}
\end{gathered}
$$

\footnotetext{
${ }^{4}$ To relate this to Roback's MWTP formulation, if we assume that housing is the only local nontraded good ( $s_{O}=$ $0)$, that all income comes from wages $\left(s_{w}=1\right)$, and that there are no income taxes $(\tau=0)$, this reduces to Roback's MWTP expression in equation (3).

5 This is similar to the approach followed by Bieri et al. (2013), who argue that estimation in two stages ensures that the implicit price of the amenity is not conflated with the implicit price of unobserved worker and housing attributes.
} 
These indices are then used to construct the QOL index in equation (6), where $\lambda_{j}^{w}$ and $\lambda_{j}^{P}$ from equations ( $\left.4^{\prime}\right)$ and (5') replace $d \ln \left(p_{j, H}\right)$ and $d \ln \left(w_{j}\right)$. Based on Albouy (2012),

$\left(s_{H}+\gamma s_{O}\right)=0.33, \tau=0.32$ and $s_{w}=0.75$. This yields the QOL index on the left-hand side of equation (7), which is then regressed on location-specific amenities.

$$
Q O L_{j} \equiv 0.33 \lambda_{j}^{P}-0.51 \lambda_{j}^{w}=\boldsymbol{A}_{j} \boldsymbol{\theta}+\xi_{j}
$$

In an important paper, Albouy and coauthors (2016) apply this approach to Public Use Microdata Area (PUMA) level data from the 2000 census to estimate the value of changes in temperature in the United States. They use flexible functional forms to relate binned temperature data to the QOL index, while controlling for other amenities. To allow for taste sorting, they apply a variant of Bajari and Benkard's (2005) local linear regression to estimate separate temperature coefficients for each PUMA. Our approach differs from theirs in focusing on winter and summer temperature. These are less comprehensive measures of temperature, but have an intuitive interpretation and capture seasonality in temperature.

\subsection{Hedonic Models That We Estimate}

We estimate two sets of hedonic models, one using traditional weights on the wage and housing price indices generated by equations ( $\left.4^{\prime}\right)$ and (5') (i.e., the weights in equation 3 ) and the other applying the weights proposed by Albouy to the same wage and housing price indices (i.e., the adjusted weights in equation 7). The national wage and property value equations we estimate use the same set of explanatory variables as the wage and housing cost hedonic equations that underpin the discrete choice model described below and are estimated using the same samples of workers and houses. Our estimates of equations (4') and (5') yield price indices for 284 MSAs; hence, we have 284 observations for our QOL models.

In view of the fact that we have a single cross section of data for 284 MSAs there are two approaches that we could take to estimating the value of winter and summer temperature using the hedonic approach. One is to assume that preferences for winter and summer temperature (and other location-specific amenities) are homogeneous and use the data to estimate the preferences of a representative individual. This would enable us to trace out MWTP for winter and summer temperature for the representative individual over the range of observed temperature values. This is consistent with the Roback model, and is the approach taken by Albouy et al. (2016) in the first part of their paper.

The other approach is to assume that preferences for temperature are heterogeneous: people living in North Dakota may value warmer winters differently than people in Florida. This is not consistent with the Roback model, which assumes homogeneous individuals, but is 
consistent with a model in which there is a continuum of locations and individuals' first-order conditions are consistent with equations 3 and 6 above (Bajari and Benkard 2005; Bajari and Kahn 2005). We believe that this is a more realistic view of the world; however, with only a single cross section of data, all we can hope to achieve is to estimate MWTP for winter and summer temperatures in the neighborhood of the temperatures observed in each city.

To implement either approach requires estimating QOL functions using a semiparametric, partially linear model (Robinson 1988). We wish to see how the QOL varies non-parametrically with winter (WT) and summer (ST) temperature, but because we have only a single cross section of data, it is important that we control for as many amenities that vary across cities as possible. Specifically, we assume that

$$
Q O L_{j}=\boldsymbol{A}_{\boldsymbol{j}} \boldsymbol{\theta}+f\left(\boldsymbol{Z}_{\boldsymbol{j}}\right)+\xi_{j}
$$

Where $\boldsymbol{A}_{\boldsymbol{j}}$ is a vector of non-climate amenities and climate amenities other than temperature, $\boldsymbol{Z}_{\boldsymbol{j}}$ $=\left(W T_{j}, S T_{j}\right)$ and $f$ is a nonparametric function. We use Robinson's estimator to obtain a $\bigvee_{n}$ consistent estimate of $\boldsymbol{\theta}, \boldsymbol{\theta} * 6$ To estimate the non-parametric part of (7'), we use a modified local linear regression, in the spirit of Albouy et al. (2016). We use the residuals $\left(\hat{e}_{j}\right)$

$$
\hat{e}_{j}=Q O L_{j}-\boldsymbol{A}_{j} \boldsymbol{\theta}^{*}
$$

where $\boldsymbol{\theta} *$ is the $\sqrt{ }_{n}$-consistent Robinson estimator ${ }^{7}$, in a local linear regression with kernel weights, as described in equation (8). In equation (8) $Z$ denotes the matrix of summer and winter temperatures, $N\left(\right.$ ) denotes the normal distribution, $b$ is bandwidth, and $\hat{\sigma}_{z}$ is the sample standard deviation of characteristic $z$. This approach yields coefficients for each MSA for summer and winter temperature, where the notation $j^{*}$ in equation (8) emphasizes this.

$$
\begin{gathered}
\boldsymbol{\Phi}_{j^{*}}=\underset{\boldsymbol{\Phi}}{\operatorname{argmin}}(\hat{\boldsymbol{e}}-\boldsymbol{Z} \boldsymbol{\Phi})^{\prime} \boldsymbol{W}(\hat{\boldsymbol{e}}-\boldsymbol{Z} \boldsymbol{\Phi}) \\
\hat{\boldsymbol{e}}=\left[\hat{e}_{j}\right] \quad \boldsymbol{W}=\left[\operatorname{diag}\left(K_{b}\left(\boldsymbol{Z}_{j}-\boldsymbol{Z}_{j^{*}}\right)\right)\right] \\
K(Z)=\prod_{\text {all } z} N\left(\left(z_{j}-z_{j^{*}}\right) / \hat{\sigma}_{z}\right) \\
K_{b}(Z)=K(b) / b
\end{gathered}
$$

\footnotetext{
${ }^{6}$ In the equation $y_{j}=\boldsymbol{A}_{j} \boldsymbol{\theta}+f\left(\mathbf{Z}_{j}\right)+\varepsilon_{j}$ a consistent estimator of $\boldsymbol{\theta}$ can be obtained by regressing $\left[y_{j}-E\left(y_{j} \mid \mathbf{Z}_{j}\right)\right]$ on $\left[\boldsymbol{A}_{j}-E\left(\boldsymbol{A}_{j} \mid Z_{j}\right)\right]$. Robinson (1988) uses kernel estimators of these conditional expectations to obtain a consistent estimator of $\boldsymbol{\theta}$.

7 In Sinha et al. (2018a) we used the residuals $Q O L_{j}-A_{j} \theta$ to estimate a local linear regression, but estimated $\theta$ using OLS following Albouy et. al. (2016). This yielded very different results than using the correct approach to handling correlation between $A_{j}$ and $Z_{j}$ (i.e., using the Robinson estimator).
} 
The estimates from equation (8) can be used to describe how MWTP for winter and summer temperature vary with temperature (i.e., they can used to describe how the preferences of a representative individual vary with temperature). They can, alternately, be used to describe MWTP for winter and summer temperature in the neighborhood of the current $\left(W T_{j}, S T_{j}\right)$ for each city, and interpreted as the outcome of taste sorting.

\section{A Discrete Choice Approach to Valuing Climate Amenities}

The discrete choice approach to amenity valuation, like the hedonic approach, assumes that households choose among geographic locations based on the utility they receive from each location, which depends on wages, housing costs, and location-specific amenities. Variation in wages, housing costs, and amenities across locations permits identification of the parameters of the household's indirect utility function.

One advantage of the discrete choice approach is that it allows the researcher to more easily incorporate market frictions, including the psychological and informational costs of moving. The traditional hedonic approach assumes that consumers are perfectly mobile and, hence, that the weighted sum of wage and housing price gradients will equal the consumer's MWTP for an amenity (equation 3). Bayer et al. (2009) demonstrate that this equality fails to hold in the presence of moving costs, and they incorporate the psychological and informational costs of leaving one's birthplace into an equilibrium model of household location choice. Barriers to mobility also imply that the assumption of national labor and housing markets, which underlies the hedonic approach, may not accurately capture wage and housing costs in different cities (Cragg and Kahn 1997).

\subsection{The Discrete Choice Model}

Our discrete choice model builds on the work of Bayer et al. (2009) and Cragg and Kahn (1997). We model household location assuming that each household selected its preferred MSA from the set of MSAs in the United States in 2000. Household utility depends on consumption of a numeraire good (the Hicksian bundle), a vector of housing characteristics and amenities, and the psychological costs of leaving the household head's birthplace. Formally, household $i$ 's utility from location $j$ is given by

$$
U_{i j}=U_{i}\left(C_{i j}, X_{i j}^{P}, A_{j} ; M C_{i j}, \xi_{j}, \varepsilon_{i j}\right)
$$


where $C_{i j}$ is consumption of the numeraire good, $\boldsymbol{X}^{\boldsymbol{P}}$ is a vector of housing characteristics, $\boldsymbol{A}_{j}$ is a vector of amenities observed by the researcher, and $\xi_{j}$ is an amenity not observed by the researcher. $M C_{i j}$ represents the psychological cost of moving to city $j$ from the head of household's birthplace. $\varepsilon_{i j}$ captures unobserved heterogeneity in preferences. Equation (9) is maximized subject to the household's budget constraint,

$$
Y_{i j}=C_{i j}+P_{j}\left(X_{i j}^{P}\right)
$$

where $Y_{i j}$ is the sum of household $i$ 's nonwage income, $I_{i}$, which is assumed not to vary by city, and the wages of all family members, $W_{i j} . P_{j}\left(\boldsymbol{X}^{\boldsymbol{P}}\right)$ is the hedonic price function in city $j$.

Following Sinha et al. (2018b), we assume that households consume the same bundle of housing characteristics in all cities and thus use $P_{i j}=P_{j}\left(X_{i 0}^{P}\right)$ to represent the expenditure of household $i$ on housing in city $j$, where $X_{i 0}^{P}$ represents household $i$ 's observed housing bundle. ${ }^{8}$ Substituting equation (10) into (9) yields the household's indirect utility function, which we assume takes the form

$$
V_{i j}=\alpha\left(Y_{i j}-P_{i j}\right)+\boldsymbol{A}_{j} \boldsymbol{\beta}_{i}+M C_{i j}+\xi_{j}+\varepsilon_{i j} .
$$

To capture preference heterogeneity, we allow the coefficients on amenities to vary across households. ${ }^{9}$ To predict the earnings of household workers and housing expenditure in locations not chosen, we estimate hedonic wage and housing price equations for each MSA, as described below.

In equation (11), $Y_{i j}$ represents income before taxes. We also estimate versions of (11) with income measured after taxes. Following Albouy et al. (2016), we use an average tax rate of 32 percent. We acknowledge that this is a very simple way of modeling taxes; however, we adopt it to make our results comparable to Albouy et al. (2016). Ideally, we would like to incorporate tax rates that are MSA-specific, although this is complicated by the fact that some MSAs cross state boundaries.

Moving costs capture the psychological, search, and out-of-pocket costs of leaving the household head's place of origin. Seventy-five percent of households in our prime-aged sample (see Table 1) live in the census region in which the head was born; 69 percent live in the same census division. Although households have been moving to warmer weather since the Second World War (Rappaport 2007), family ties and informational constraints may have prevented this

\footnotetext{
8 This assumption can be relaxed by estimating the model described in equations 9' - 11' below, which allows the housing bundle to vary across cities. See Table A.6.

${ }^{9}$ In Sinha et al. (2018b), we allow the coefficient on $Y_{i j}-P_{i j}$ to vary across households. We also allow $Y_{i j}-P_{i j}$ to enter the utility function in quadratic form.
} 
from occurring more completely. As shown in section 5.2, failure to account for these costs significantly alters the value attached to climate amenities.

Following Bayer et al. (2009), we represent moving costs as a series of dummy variables that reflect whether city $j$ lies outside of the state, census division, or census region in which household $i$ 's head was born. Formally,

$$
M C_{i j}=\pi_{0} d_{i j}^{\text {state }}+\pi_{1} d_{i j}^{\text {division }}+\pi_{2} d_{i j}^{\text {region }}
$$

where $d_{i j}$ State denotes a dummy variable that equals 1 if $j$ is in a state that is different from the one in which household head $i$ was born, $d_{i j}{ }^{\text {Division }}=1$ if MSA $j$ is outside of the census division in which the household head was born, and $d_{i j}$ Region $=1$ if MSA $j$ lies outside of the census region in which the household head was born. ${ }^{10}$

\subsection{Estimation of the Discrete Choice Model}

Estimating the location choice model requires information on the wages that a household would earn and on the cost of housing in all MSAs. Because wages are observed only in the household's chosen location, we estimate a hedonic wage equation for each MSA and use it to predict $W_{i j}$. The hedonic wage equation for MSA $j$ regresses the logarithm of the hourly wage rate for worker $m$ in MSA $j$ on variables $\left(\boldsymbol{X}_{m j}^{w}\right)$, measuring the demographic characteristicseducation, experience, and industry, and occupation—of worker $m$.

$$
\ln w_{m j}=\gamma_{j}^{2}+\boldsymbol{X}_{m j}^{w} \Gamma_{j}^{X, 2}+v_{m j}^{2} \forall j=1, \ldots, J
$$

Equation (13) is identical to equation (4) above but allows the coefficients on $X^{w}$ to vary by MSA. It is estimated using data on full-time workers in the PUMS. ${ }^{11}$ The coefficients of (13) are used to calculate the earnings of each worker in the sample used to estimate the discrete choice model, under the assumption that individuals work the same number of hours and weeks in all locations. Summing earnings over all individuals in each household, we obtain predicted household wages for household $i$ in location $j\left(\hat{W}_{i j}\right)$.

\footnotetext{
10 Allowing moving costs to vary by marital status or by presence of children makes little difference to our results (see Sinha et al. 2018b).

11 We have also estimated equation (13) allowing for nonrandom sorting (Dahl 2002). Specifically, we compute the probability of moving from each birthplace to current location (in terms of census divisions) conditional on each education group listed in Table 1 by taking the appropriate cell counts in our sample of workers (close to 3 million individuals). Including this probability correction term (in quadratic form) in equation (13) has minimal impact on our wage regression results, possibly due to the inclusion of industry and occupation indicators in the equation.
} 
The cost of housing in each location is estimated based on hedonic property value equations for each MSA,

$$
\ln P_{i j}=\delta_{j}^{2}+\boldsymbol{X}_{i j}^{P} \boldsymbol{\Delta}_{j}^{X, 2}+\eta_{m j}^{2} \forall j=1, \ldots, J
$$

$P_{i j}$ is the annual cost of owning house $i$ in city $j$, computed as the sum of the monthly mortgage payment or rent and the costs of utilities, property taxes, and property insurance. $\boldsymbol{X}_{i j}^{P}$ contains a dummy variable indicating whether the house was owned or rented, as well as a vector of dwelling characteristics. Utility costs are added both to the costs of owning a home and to rents because heating and cooling requirements vary with climate. We wish to separate these costs from climate amenities. Equation (14) is estimated separately for each MSA in our dataset. We predict housing expenditures for household $i$ in city $j$ assuming that the household purchases the same bundle of housing characteristics in city $j$ as it purchases in its chosen city.

This is clearly a strong assumption. To test its validity, we examine the mean value of key housing characteristics (number of bedrooms and number of rooms) and their standard deviation across MSAs for different household groups, characterized by income group and household size. The coefficient of variation for number of bedrooms and number of rooms within income and household size groups averages only $0.07-0.08$, suggesting that households of similar size and income tend to live in dwellings of similar characteristics, thus supporting our methodology for predicting housing expenditures.

As a sensitivity analysis, we estimate a location choice model that uses a housing price index, following Bayer et al. (2009), rather than predicting housing expenditures in each MSA. In Bayer et al. (2009), utility is assumed to be of the Cobb Douglas form (9'), which is maximized subject to $\left(10^{\prime}\right) .{ }^{12} \mathrm{H}$ is housing consumption, and $\rho_{j}$ is the housing price index in city $j$. This implies that indirect utility $\left(11^{\prime}\right)$ is a function of a housing price index $\rho_{j}$ that varies across cities, not households. ${ }^{13}$

$$
\begin{gathered}
U_{i j}=C_{i j}^{\alpha_{C}} H_{i j}^{\alpha_{H}} e^{M C_{i j}} e^{\boldsymbol{A}_{j} \boldsymbol{\beta}_{i}} e^{\xi_{j}} e^{\varepsilon_{i j}} \\
C_{i j}+\rho_{j} H_{i j}=Y_{i j} \\
\ln V_{i j}=\alpha_{0}+\alpha_{Y} \ln Y_{i j}+M C_{i j}-\alpha_{H} \ln \rho_{j}+\boldsymbol{A}_{j} \boldsymbol{\beta}_{i}+\xi_{j}+\varepsilon_{i j}
\end{gathered}
$$

\footnotetext{
12 In Bayer et al. (2009) the vector of amenities does not enter the utility function exponentially.

${ }^{13}$ The housing price index for each MSA is the estimated MSA fixed effect in the national hedonic housing price equation, equation (5').
} 
The results of estimating the hedonic wage and housing market equations for all cities are summarized in Appendix Tables A.1 and A.2. We find, as do Cragg and Kahn (1997), that the coefficients in both sets of hedonic equations vary significantly across MSAs, suggesting that the assumption of national labor and housing markets made in hedonic studies is inappropriate.

We estimate the discrete location choice model (equation 11) in two stages. The first is a mixed logit model in which the indirect utility function incorporates unobserved heterogeneity in preferences for winter and summer temperature, and MSA fixed effects $\left(\delta_{j}\right)$ :

$$
V_{i j}=\alpha\left(\hat{Y}_{i j}-\hat{P}_{i j}\right)+W T_{j} \beta_{i}^{W T}+S T_{j} \beta_{i}^{S T}+M C_{i j}+\delta_{j}+\varepsilon_{i j}
$$

We assume that the temperature coefficients $\left(\beta^{W T}\right.$ and $\left.\beta^{S T}\right)$ are jointly normally distributed, with mean vector $\boldsymbol{\mu}$ and variance-covariance matrix $\boldsymbol{\Sigma}$. The elements of $\boldsymbol{\Sigma}$ are estimated in the first stage. However, since the MSA fixed effects encompass all local attributes that do not vary across households, the mean vector $\boldsymbol{\mu}$ is contained in $\delta_{j}$, and thus, is estimated in the second stage (Murdock 2006). We interpret the error term $\varepsilon_{i j}$ as combining the error in predicting household $i$ 's wages and housing expenditures in city $j$ with household $i$ 's unmeasured preferences for city $j$. Assuming that the idiosyncratic errors are independently and identically distributed Type I extreme value, the probability of household $i$ selecting city $j$ is given by the mixed logit model,

$$
P(\text { i selectes } j)=\int_{-\infty}^{\infty} \frac{\exp \left(V_{i j}\left(\alpha, \boldsymbol{\beta}_{i}, \boldsymbol{\pi}\right)\right)}{\sum_{k} \exp \left(V_{i k}\left(\alpha, \boldsymbol{\beta}_{i}, \boldsymbol{\pi}\right)\right)} f(\boldsymbol{\beta} \mid \boldsymbol{\mu}, \boldsymbol{\Sigma}) d \beta
$$

The parameters of equation (16) are estimated via simulated maximum likelihood techniques, using a choice set equal to the household's chosen alterative and a sample of 59 alternatives from the set of 284 MSAs. ${ }^{14}$

In the second stage of our model, equation (17) is estimated by ordinary least squares (Berry et al. 2004).

\footnotetext{
14 The validity of the McFadden sampling procedure (McFadden 1978) hinges on the independence of irrelevant alternatives, which does not hold in the mixed logit model. Nerella and Bhat (2004) use simulated data to examine the effect of sampling on the empirical accuracy of parameter estimates in a mixed logit model. They suggest using at least one-quarter of the universal choice set in estimating a mixed logit model. We do, however, face computational trade-offs in estimating the mixed logit model using more than one-quarter of the universal choice set and a sample large enough to estimate 284 fixed effects with precision. Experiments with the size of the choice set indicate that increasing the size of the choice set beyond 60 MSAs does not significantly alter parameter estimates.
} 


$$
\delta_{j}=\boldsymbol{A}_{\boldsymbol{j}} \Gamma+\xi_{j}
$$

To examine how taste heterogeneity varies by location, we compute the distribution of $\boldsymbol{\beta}_{\mathrm{i}}$ for each household, conditioning on where the household has chosen to locate. Specifically, we use Bayes' rule (Revelt and Train 1999) to derive the distribution of $\boldsymbol{\beta}_{\mathrm{i}}$ conditional on chosen location, household attributes, and the population distribution of $\boldsymbol{\beta}$,

$$
h\left(\beta \mid \text { choice }_{i}, X_{i}, \boldsymbol{\mu}, \boldsymbol{\Sigma}\right)=\frac{\operatorname{Pr}\left(\text { choice }_{i} \mid X_{i}, \beta\right) f(\beta \mid \boldsymbol{\mu}, \boldsymbol{\Sigma})}{\operatorname{Pr}\left(\text { choic }_{i} \mid X_{i}, \boldsymbol{\mu}, \boldsymbol{\Sigma}\right)}
$$

Using this conditional distribution yields an expression for mean taste parameters, $\boldsymbol{\mu}_{\boldsymbol{i}}$, for households of type $X_{i}$ :

$$
\mu_{i}=E\left(\beta_{i} \mid \text { choice }_{i}, X_{i}, \boldsymbol{\mu}, \boldsymbol{\Sigma}\right)=\int \beta_{i} h\left(\beta \mid \text { choice }_{i}, X_{i}, \boldsymbol{\mu}, \boldsymbol{\Sigma}\right) d \beta
$$

These household-level parameters are estimated via simulation. Taking the average over all households in each MSA and dividing by the coefficient on the Hicksian bundle yields average MWTP for all households in a given MSA. A similar method can be used to derive the conditional variance-covariance matrix $\boldsymbol{\Sigma}_{\boldsymbol{i}}$.

\section{Data and Empirical Specifications}

The data used to estimate our discrete choice and hedonic models come from the 5 percent PUMS of the 2000 census as well as other publicly available data sources.

\subsection{Data Used to Estimate Hedonic Price Functions}

The variables that we include in the hedonic wage and housing price equations (equations 4', 5', 13, and 14) are listed in Appendix Tables A.1 and A.2, together with coefficient estimates. The hedonic wage equation is estimated using all persons in the 2000 PUMS who live in an MSA for which we have complete amenity data and work at least 40 weeks per year and between 30 and 60 hours per week. ${ }^{15}$ Persons who are self-employed, in the military, or in farming, fishing, or forestry are excluded from the sample. The housing equations are estimated using data on all households living in one of the 284 MSAs for which we have complete amenity data.

\footnotetext{
15 There were 284 such MSAs in the continental United States in 2000, containing 80 percent of the country’s population.
} 


\subsection{Households Used to Estimate the Discrete Choice Model}

In estimating the discrete choice models, we focus on households residing in one of the 284 MSAs for which we have complete amenity data. To be included in our sample, a household must be headed by a person 16 years of age or older who was born in the continental United States. We exclude households whose heads are in the military or are in certain occupations (e.g., logging, mining) that would restrict locational choices. We also eliminate households whose members are self-employed, because of the difficulty in predicting their wages, and drop households with negative values of $Y_{i j}-P_{i j}$ at their chosen locations. ${ }^{16}$ This leaves over 2 million households. A 2.5 percent sample of these households yields the 54,008 households described in Table $1 .{ }^{17}$

We have estimated the discrete choice model for the full sample of households and also for the two subsamples described in Table 1: households with prime-aged heads (i.e., heads between 25 and 55) and households with heads over age 55 . The results presented in this paper focus on households with prime-aged heads. As Table 1 indicates, 98 percent of these households have some labor income, and on average, 93 percent of the income of these households comes from wages. The hedonic approach, which uses wage and housing cost differentials to value amenities, is most appropriately applied to prime-aged households. Our results also suggest that preferences for climate amenities differ significantly between primeaged households and households with older heads; hence, focusing on a single demographic group makes for a cleaner comparison with the hedonic approach.

\subsection{Climate Variables}

Previous studies of the value of climate amenities have used various measures of climate, including temperature, humidity, precipitation, and sunshine. Many studies use average summer and winter temperatures (Graves and Mueser 1993; Cragg and Kahn 1997, 1999; Kahn 2009) ${ }^{18}$ or annual heating and cooling degree days (Roback 1982; Blomquist et al. 1988; Gyourko and Tracy 1991; Albouy 2012), ${ }^{19}$ which are highly correlated with winter and summer temperatures. In studying the impact of climate on agriculture, health, and electricity usage, temperature has

\footnotetext{
16 These households may have substantial accumulated wealth (e.g., in real property) that we cannot measure.

17 Computational difficulties led us to use such a small sample of households. However, we have run the mixed logit model on different samples of this size and find the results to be sufficiently similar.

18 Graves and Mueser (1993) and Kahn (2009) use mean January and mean July temperatures; Cragg and Kahn $(1997,1999)$ use mean February and mean July temperatures.

${ }^{19}$ A mean daily temperature greater than 65 degrees $\mathrm{F}$ results in (average temperature -65 ) cooling degree days. A mean daily temperature less than 65 degrees results in (65 - average temperature) heating degree days.
} 
been measured by the number of days in various temperature bins (Schlenker and Roberts 2009; Deschenes and Greenstone 2011; Barreca et al. 2016). In the context of climate amenities, Fan et al. (2016) use the number of days below 32 degrees and the number of days above 80 degrees, while controlling for mean annual temperature. Albouy et al. (2016) use binned data to examine the impact of temperatures above and below 65 degrees F.

Our hedonic and discrete choice models use mean winter (December-February) and mean summer (June-August) temperatures, measured as climate normals for the period 19702000. The advantage of mean winter and summer temperatures is that they capture seasonality, which annual heating and cooling degree days and temperature bins do not. Also, with the MSA as the unit of observation, it is asking a lot of the data to estimate the impact of temperature when measured as the number of days in fine temperature bins. ${ }^{20}$

In interpreting temperature coefficients, we note that correlation between winter and summer temperatures and temperatures during other seasons of the year implies that winter and summer temperatures will pick up other temperature impacts: the correlation between mean winter temperature and mean March temperature is 0.98 , as is the correlation between mean winter temperature and mean November temperature. Collinearity among mean winter, summer, fall, and spring temperatures, however, makes it impossible to include all four measures in our models.

In the discussion that follows, we focus primarily on results for winter and summer temperatures; however, the hedonic and discrete choice models also include annual snowfall, mean summer precipitation, and July relative humidity. The climate variables in the models are summarized in Table 2. All variables are climate normals: the arithmetic mean of a climate variable computed for a 30 -year period. ${ }^{21}$ Following the literature, we also include the percentage of possible sunshine, defined as the total time that sunshine reaches the surface of the earth, expressed as a percentage of the maximum amount possible from sunrise to sunset.

\subsection{Nonclimate Amenities}

The nonclimate amenity variables used in both the discrete choice and hedonic models are also summarized in Table 2. These include amenity measures typically used in QOL studies as well as variables that are likely to be correlated with climate, such as elevation, visibility, and

\footnotetext{
${ }^{20}$ Moreover, the number of days per year exceeding 80 degrees_-based on climate normal for 1970-2000—is very small.

21 The temperature and summer precipitation data are for the period 1970-2000. July relative humidity, annual snowfall, and percentage possible sunshine are measured for the period 1960-1990.
} 
measures of parks and recreation opportunities. Because both sets of models are estimated using a single cross section of data, we attempt to avoid problems of omitted variable bias by including a variety of location-specific amenities in our models.

Many QOL studies include population density as an amenity variable (Roback 1982; Albouy 2012) or city population (Gyourko and Tracy 1991). Population should be used with caution in a discrete choice model, since the model is constructed to predict the share of population in each city (i.e., summing the predicted probability of moving to city $j$ across households yields the predicted share of population in city $j$ ). We therefore do not include population as an amenity but do include population density, which may proxy amenities that higher population density supports that are not adequately captured by other variables (e.g., better public transportation, restaurants, and live sporting events). We also estimate models with population density omitted. ${ }^{22}$

Other (dis)amenities for which we control include air pollution (fine particulate matter, $\mathrm{PM}_{2.5}$ ), an index of violent crime, visibility (percentage of hours with visibility greater than 10 miles), square miles of parks within the MSA, elevation measured at the population-weighted centroid of the MSA, and distance from the population-weighted centroid of each MSA to the nearest coast. We also include indices from the Places Rated Almanac (Savageau and D’Agostino 2000) that measure how well each city functions in terms of transportation, education, health, and recreation opportunities.

\subsection{Empirical Specification}

The hedonic wage and price equations we estimate are semilog functions, a form commonly used in the hedonic literature and used by Albouy et al. (2016) in constructing location-specific wage and housing price indices. When estimating QOL and discrete choice models (e.g., equations (7') and (17)), amenities other than winter and summer temperature enter the models in linear or logarithmic form.

To examine heterogeneity in tastes for climate, we focus on winter and summer temperatures. In hedonic models, the residuals obtained by estimating equation (7') as a partially linear semiparametric model are used to estimate local linear regressions (equation 8), which allow MWTP for summer and winter temperatures to vary by city. In estimating discrete choice

\footnotetext{
22 We recognize that ideally we would want to instrument for population density. Although we do not instrument for population density, we conduct sensitivity analysis by replacing population density with other variables. The results indicate that the MWTP estimates are robust to these alternative specifications. See Sinha et al. (2018b) for details.
} 
models, we allow the coefficients on winter and summer temperatures to be random. Specifically, we assume that the coefficients are jointly normally distributed with variancecovariance matrix $\Sigma$. ${ }^{23}$ We compute the distribution of these coefficients for each sample household, conditional on its chosen MSA, and then average the means of these location-specific coefficients for all households in a city to compute MSA-specific MWTP for winter and summer temperatures. $^{24}$

\section{Estimation Results}

In the spirit of Cragg and Kahn (1997) and Bayer et al. (2009), we compare estimates of mean MWTP from the discrete choice and hedonic models to see whether the discrete choice approach yields similar mean estimates of amenity values. We are, however, also interested in taste sorting. From the perspective of valuing climate, it matters how MWTP for temperature changes varies geographically: Are households living in areas where temperatures are likely to increase under future climate scenarios willing to pay more (or less) than the mean for warmer winters or cooler summers? We approach this by measuring MWTP for temperature changes conditional on a household's current location.

\subsection{Hedonic Results}

We begin by examining how climate amenities are capitalized into wages and housing prices, based on national hedonic price functions. Columns 1 and 2 of Table 3 present climate coefficients from the hedonic wage and housing price regressions estimated when the MSA wage and housing price indices from equations $\left(4^{\prime}\right)$ and $\left(5^{\prime}\right)$ are each regressed on the vector of cityspecific amenities. ${ }^{25}$ The last two columns of the table show the climate amenity coefficients obtained when the QOL indices formed from the MSA wage and housing price indices are regressed on a vector of amenities, following equation (7).

Table 3 suggests that winter temperature is an amenity that is capitalized primarily into wages (i.e., wages are lower in MSAs with warmer winters) and summer temperature is a disamenity that is capitalized primarily into housing prices (i.e., housing prices are lower in

\footnotetext{
23 In Sinha et al. (2018b), we allow other climate variables to have random coefficients, as well as the coefficients on moving costs and the Hicksian bundle. These alternative specifications have virtually no impact on mean MWTP for winter or summer temperature. The sorting patterns we observe for winter and summer temperatures are qualitatively similar to those we report below.

24 Mean MWTP for winter temperature in an MSA is computed by averaging the means of the winter temperature distributions for all households in the MSA and dividing by $\alpha$, the coefficient on the Hicksian bundle.

25 The coefficients of nonclimate amenities are presented in Appendix Table A.3.
} 
MSAs with hotter summers). Housing prices are higher in MSAs with more sunshine but lower in areas with more snowfall. At the same time, wages are lower in MSAs with more snowfall.

The wage and housing prices indices from equations $\left(4^{\prime}\right)$ and $\left(5^{\prime}\right)$ are combined into QOL indices using traditional (Roback) weights (column 3) and adjusted (Albouy) weights (column 4). Interestingly, the simple correlation between the two sets of QOL indices is low $(r=0.2)$, suggesting that the two sets of weights give very different ranking to cities. In the QOL models in columns (3) and (4) winter and summer temperature enter in linear form, in order to illustrate, as simply as possible, the impact of the two different sets of weights in valuing local amenities. The Albouy weights, which assign more importance to housing prices, suggest that summer temperature is more of a disamenity than winter temperature is an amenity; traditional weights, which assign more weight to wages, assign a higher amenity value to winter temperature. As Table A.3 shows, whether a city characteristic is an amenity or a disamenity may differ between the two sets of weights: for example, population density is an amenity using adjusted weights but a disamenity using traditional weights.

We now consider how QOL varies nonparametrically with winter and summer temperature. Prior to presenting the results of the local linear regression model in equation (8), we consider a simpler nonparametric model. Specifically, we estimate the partially linear, semiparametric model in (7') allowing only one temperature variable at a time to enter the model nonparametrically. We first include summer temperature in the linear portion of the model (effectively assuming that MWTP for summer temperature is constant and independent of location) and estimate $f(W T) .{ }^{26}$ Then, we do the reverse, controlling for winter temperature in linear part of the model and estimating $f(S T)$ nonparametrically.

Figures 1 and 2 display the results of allowing winter and summer temperature to separately enter equation (7') nonparametrically. ${ }^{27}$ Figure 1 displays the results using adjusted (Albouy) weights and Figure 2 the results using traditional weights. ${ }^{28}$ Figures $1 \mathrm{~A}$ and 2A indicate that higher winter temperature is an amenity at most, but not all temperatures: the QOL index decreases with winter temperature at very low temperatures, but increases with winter temperature between 15 and 60 degrees. It continues to increase after 60 degrees using adjusted weights, but not using traditional weights. The QOL index increases with summer temperature between 60 and 65 degrees, suggesting, as do Albouy et al. (2016), that people prefer a summer

\footnotetext{
${ }^{26}$ We estimate this using the Stata Semipar command, which computes the Robinson estimator for a model in which only a scalar variable enters nonparametrically.

27 The $\boldsymbol{\theta}^{*}$ coefficients from these models appear in Appendix Table A.4.

${ }^{28}$ The vertical axis in Figures 1 and 2 is the QOL index. Temperature is represented on horizontal axis.
} 
at 65 to a summer at 60 degrees. The QOL index, however, decreases with summer temperature, for temperatures between 65 and 84 degrees, using both sets of weights. We note that the models estimated with adjusted weights fit the data better (see Table A.4). As there are also a priori reasons for using adjusted weights (Albouy 2012), we focus, henceforth, on these results.

Figures 3A and 3B can be used to calculate MWTP for changes in winter and summer temperature when both temperature variables enter equation $\left(7^{\prime}\right)$ nonparametrically. ${ }^{29}$ The vertical axis of each graph shows the fraction of income that would be given up for a 5-degree change in temperature, measured from the previous temperature. To illustrate, in Figure 3A an increase in mean winter temperature from 10 to 15 degrees is worth $1 \%$ of income (or $0.2 \%$ of income per degree), although the effect is not significantly different from zero. ${ }^{30}$ Figure 3A suggests that people are willing to pay very little to increase temperature from 10 to 25 degrees but that MWTP for higher winter temperatures increases beyond 25 degrees. Indeed, MWTP is highest for an increase in temperature from 45 to 50 degrees. At a mean income of $\$ 69,161$, MWTP for a one-degree increase in temperature between 45 and 50 degrees is about $\$ 350$ per degree. MWTP declines after 50 degrees, although point estimates are less precise.

The corresponding figure for summer temperature (Figure 3B) indicates that MWTP for cooler summers is positive after 65 degrees, but that people are willing to pay less to reduce summer temperature from 80 to 85 degrees than they are to reduce it from 75 to 80 degrees.

An alternate way to present the impact of temperature on MWTP is from a taste sorting perspective - to calculate MWTP for winter temperature in each city, evaluated at the summer temperature in that city, and likewise for summer temperature. These values are plotted against mean winter (summer) temperature, for each city, in Figures 4 and 5, to show patterns of taste sorting based on the hedonic model with adjusted weights. With only 284 observations, results are sensitive to the bandwidth chosen for the kernel weights in equation 8. ${ }^{31}$ In general, the smaller the bandwidth, the greater the range of estimated MWTP values across cities. The MWTP for winter and summer temperatures for each city are plotted using adjusted weights in Figures 4 and 5 using a bandwidth of 0.7 and in Appendix Figures A.1-A.4 for both sets of weights using bandwidths between 0.4 and 0.9 .

\footnotetext{
${ }^{29}$ The graphs in Figure 3 were produced by estimating equation ( $\left.7^{\prime}\right)$ using the Stata Npregress command with optimal bandwidths chosen by cross-validation.

30 The estimates in the winter (summer) temperature graph have been averaged across summer (winter) temperatures. To illustrate, MWTP for an increase in winter temperature from (e.g.) 15 to 20 degrees was computed by averaging this value across all summer temperatures.

31 The optimal bandwidth in equation 8 should be $\mathrm{O}\left(\mathrm{n}^{-1 / \mathrm{q}^{+4}}\right)$ where $\mathrm{q}$ is the number of covariates in $\mathrm{Z}$ ( $\mathrm{Li}$ and Racine 2007). In our case $n^{-1 / 6}=0.39$.
} 
In Table 4, we present summary statistics of MWTP from the local linear regressions in (8) using bandwidths between 0.4 and 0.9 . When preferences for temperature are allowed to vary across cities, both hedonic models suggest that (on average) summer temperature is a greater disamenity than winter temperature is an amenity. Focusing on the models using adjusted weights, the MWTP for warmer winters averaged across all cities is about one-third of the mean MWTP for cooler summers. At a bandwidth of 0.5 (0.7), mean MWTP for winter temperature is \$189 (\$174) using adjusted weights. Mean MWTP to reduce summer temperature by 1 degree is \$558 (\$536). Table 4 also indicates that mean MWTP for summer temperature is negatively correlated with summer temperature (correlation coefficient $\approx-.50$ ), which is consistent with Figure 3B. MWTP for winter temperature is weakly negatively correlated with winter temperature, which is consistent with Figure 3A.

Figures 4 and 5 display the sorting patterns implied by equation (8) when the hedonic model is estimated using Albouy weights. Figure 4 displays MWTP for winter temperature by city, plotted against winter temperature; Figure 5 is the corresponding figure for summer temperature. The sorting pattern for winter temperature in Figure 4 is consistent with Figure 3A. There is positive correlation between MWTP for winter temperature and winter temperature between 20 and 45 degrees, but negative correlation below 20 degrees and above 45 degrees. Cities in South (in the West South Central and South Atlantic regions) with a mean winter temperature of 45 degrees or higher have below-average MWTP for winter temperature. Cities on the Pacific Coast with mean winter temperatures above 45 degrees, however, have aboveaverage MWTP for winter temperature. Households who live in cold cities, in general, have MWTP for winter temperature that is above mean MWTP for all cities in our sample. This sorting pattern suggests that households in northern latitudes - in the East and West North Central and New England census divisions-would be willing pay the more for the beneficial portion of climate change than households in Texas and Florida.

Figure 5 indicates that for most cities with mean summer temperatures over 73 degrees (the sample mean) MWTP for cooler summers is above average MWTP; most cities with mean summer temperature below 73 degrees have a below-average MWTP for cooler summers. Cities in the South Atlantic and East South Central regions have above-average MWTP to reduce summer temperature, as do cities in Southern California. Cities in Pacific Northwest have below-average MWTP for cooler summers.

\subsection{Discrete Choice Results}

As noted above, we have estimated discrete location choice models for various population groups: households headed by persons between 25 and 55 (prime-aged households), 
households whose heads are over 55, and households headed by persons 16 years of age and older (full sample). In comparing the discrete choice and continuous hedonic approaches, we focus on prime-aged households because of their strong labor-force attachment (see Table 1).

Table 5 presents estimates of MWTP for winter and summer temperatures based on four mixed logit models. ${ }^{32}$ Our base model (model M.1) controls for all the amenities in Table 2, as well as moving costs, and allows the coefficients on winter and summer temperatures to be jointly normally distributed. Model M.2 is identical to model M.1, except that income is measured as after-tax income. Both models suggest that on average, higher winter temperature is an amenity and warmer summer temperature a disamenity. Mean MWTP to reduce summer temperature by 1 degree is higher than mean MWTP to increase winter temperature by 1 degree (\$627 versus \$518 in model M.1; \$522 versus \$382 in model M.2). There is, however, considerable variation in tastes.

Interestingly, the coefficients on winter and summer temperatures are negatively correlated: most (but not all) households that prefer milder winters also prefer milder summers, while those that favor colder winters like hotter summers. ${ }^{33}$ The significant negative correlation between MWTP for winter and summer temperature $(r=-0.7)$ gives rise to the sorting patterns described below. We note that in the hedonic model with adjusted weights (Table 4), MWTP for winter and summer temperature are very weakly correlated $(r=-0.15)$.

To examine how households sort across locations in relation to their taste for winter and summer temperatures, we calculate the joint distribution of the coefficients of winter and summer temperatures for each household, conditional on the household's choice of location. The means of these conditional distributions are averaged across all households in each city, divided by the coefficient on the Hicksian bundle, and plotted against city temperature in Figures 6 and $7^{34}$

32 MWTPs for amenities other than winter and summer temperture are reported in Appendix Table A.5.

33 Appendix Table A.6 explores the sensitivity of the discrete choice model to the Hicksian bundle entering equation (11) in quadratic form and to the use of the Cobb-Douglas utility function (equation 11'). Results are robust to these sensitivity analyses.

34 When preferences for winter and summer temperatures are forced to be uncorrelated, there is a strong association between MSA mean MWTP for higher temperature and temperature itself: the correlation is 0.96 between MSA mean MWTP and winter temperature and 0.97 between MSA mean MWTP and summer temperature. It appears that households that live in warmer cities place higher values on both summer and winter temperatures. 
The pattern of taste sorting is similar whether we base location decisions on income before or after taxes. ${ }^{35}$ Households with higher MWTP for warmer winters tend to locate in warmer cities: the correlation coefficient between winter temperature and mean MSA MWTP is 0.92 in model M.1 (Figure 6A) and 0.91 in model M.2 (Figure 6B). There is, however, some variation in mean MWTP across cities at a given temperature. For example, at a mean winter temperature of 40 degrees, households in the states of Oregon and Washington have a willingness to pay for a warmer winter that is much higher than the MWTP of households in Texas. At a mean winter temperature of 50 degrees, households on the Pacific coast are willing to pay more for warmer winter temperature than households in the East South Central division.

The relationship between MWTP for a 1 degree increase in summer temperature (Figures 7A and 7B) and summer temperature is an inverted U. While MWTP for an increase in summer temperature is negative in all cities except 2 in the West North Central census division, households in the South Atlantic and Pacific divisions have the greatest MWTP to reduce mean summer temperature by 1 degree. ${ }^{36}$ The higher MWTP for cooler summers in Florida than in North Dakota does not reflect the fact that summer temperature is higher in Florida than in North Dakota: MWTP is the value of a small change in temperature from current temperature levels. The higher MWTP to reduce summer temperature reflects the fact that people living in Florida are in the tails of the taste distribution for both winter and summer temperature- they have a higher than average MWTP to increase winter temperature and a higher MWTP than average to reduce summer temperature-they are climate sensitive. People living in North Dakota, in contrast, are not very climate sensitive and have small MWTP for both winter and summer temperatures.

Figures 6 and 7 suggest that, holding temperature constant, MWTP for winter and summer temperatures varies by region: households in the East North Central census division appear to find hotter summers less of a disamenity than households that have located on the Pacific coast. Households in the Mountain states appear to favor colder winters than households in the Pacific division. Some of this might appear to reflect differences in climate variables other than temperature, such as differences in summer humidity, precipitation, and snowfall. Our base

\footnotetext{
35 Figures 6A and 7A plot results based on model M.1, while Figures 6B and 7B plot results from model M.2, which is based on net-of-tax income.

${ }^{36}$ The correlation between mean summer temperature and MWTP for summer temperature in Figure 7B is -0.38 . If we restrict preferences over winter and summer temperatures to be uncorrelated, we find a strong positive correlation between MWTP for summer temperature and the temperature of the city in which the household livessee footnote 34 .
} 
model, however, controls for summer humidity and precipitation, as well as snowfall and sunshine.

Failure to control for moving costs has a large effect on the estimated value of climate amenities, as well as on the spatial distribution of MWTP for winter and summer temperatures. Model M.3 (M.4) shows the impact of dropping moving costs from the discrete choice model when income is measured before (after) taxes. While the mean of the distribution of MWTP for winter temperature remains positive, its magnitude drops by about 5 percent (15 percent). The mean of the distribution on the coefficient of summer temperature is even more sensitive: its magnitude drops by about 38 percent (35 percent) when moving costs are omitted. Table 5 also indicates the role that moving costs play in taste sorting: when moving costs are omitted from the base models, the standard deviations on the winter temperature coefficients are no longer statistically significant. In model M.3, the correlation coefficient between the winter and summer temperature coefficients switches from negative to positive in sign. Simply put, patterns of taste sorting are no longer identified when moving costs are removed from the discrete choice model.

This is borne out in Figure 8, which contrasts the sorting patterns from model M.3 when moving costs are removed with the patterns shown in Figures 6B and 7B. The top right panel of Figure 8 still shows a positive correlation between mean MWTP for winter temperature and mean winter temperature; however, the variation is small, and all MSAs have mean MWTP within about \$20 of each other. The bottom right panel suggests that MWTP for warmer summers is positively associated with summer temperature. ${ }^{37}$ Omitting moving costs makes it appear, incorrectly, that people sort according to summer temperature, and that people living in hotter areas will pay less to reduce summer temperature than those who live in locations with cooler summers - i.e., that people who live in Florida and Texas have a lower than average MWTP to reduce summer temperature. The fact is that approximately $80 \%$ of the people who lived in the South Atlantic and West South Central census divisions in 2000 were born there. But, part of the reason that they live there is that the costs of moving from their birthplace are high. When we ignore moving costs, it appears that people in the South actually like warmer summers.

We present these results to show the importance of controlling for moving costs. Moving costs are highly significant in all discrete choice models and clearly belong in the models.

37 Similar results obtain when using income before adjusting for taxes (see Sinha et al. (2018b), Figure 3). 


\subsection{Comparison of Hedonic and Discrete Choice Results}

When comparing the results from the hedonic model (equation (8) estimated with Albouy weights) and the discrete choice model (model M.2 of Table 5) estimated using the same underlying data, two results stand out: The first is that mean MWTP for cooler summers, averaged across all 284 MSAs, is approximately the same using the two models. Mean MWTP for warmer winters is about twice as high using the discrete choice model as using the hedonic model.

More importantly, the hedonic and discrete choice approaches produce very different taste sorting patterns. The discrete choice models suggest that households sort across locations based on preferences for winter temperature: there is a strong positive correlation between winter temperature and MWTP for winter temperature in Figure 6B. The relationship between MWTP for winter temperature and MSA temperature resulting from hedonic model (Figure 4) is quite different. The hedonic model estimates that, at mean winter temperatures below 45 degrees, MWTP for WT is above the average MWTP in virtually all cities; above 45 degrees, cities in Texas, Florida are Arizona are willing to pay less than the average MWTP for warmer winters. More simply put; the correlation between MWTP for winter temperature is approximately - 0.40 based on the hedonic model; whereas it is 0.96 using the discrete choice model.

The two models also produce different sorting patterns for summer temperature. A key result from the discrete choice model is that preferences for warmer summers and warmer winters are negatively correlated. This leads to the inverted-U sorting pattern shown in Figure 7B. Households on the Pacific coast, which have high MWTP for warmer winters, also have a high MWTP for cooler summers. The same is true of households that live in the South Atlantic division. Both are climate sensitive households. In contrast, the sorting pattern produced by the hedonic model shows a much stronger negative slope: according to this model, households in Texas and Florida have the highest MWTP to avoid hotter summers, but households on the Pacific coast have the lowest MWTP for cooler summers.

\subsection{What Accounts for the Differences?}

Why do estimates of the amenity value of temperature differ between the two approaches? The discrete choice and hedonic models we have estimated differ in three ways: (1) the discrete choice model incorporates the psychological costs of moving from one's birthplace,

which the hedonic models do not; (2) the discrete choice model allows for city-specific labor and housing markets, rather than assuming a national market; (3) the discrete choice model uses 
information on market shares (i.e., population), which the hedonic model does not. ${ }^{38}$ We explore each of these possible explanations for the differences between the results produced by the two models.

If moving costs prevent amenity values from being fully capitalized into wages and housing prices, then failure to account for moving costs in the hedonic model should reduce MWTP estimates compared with those produced by the discrete choice model. Equivalently, removing moving costs from the discrete choice model should cause discrete choice estimates of MWTP to fall. This is indeed what happens in the mixed logit models. In Table 5, dropping moving costs reduces estimates of mean MWTP for winter and summer temperatures: mean MWTP for winter temperature is about 15\% lower in model M.2. than in model M.4; mean MWTP for summer temperature is about 35\% lower. More importantly, it is moving costs that identify taste sorting patterns in the discrete choice model. Removing them reverses the taste sorting patterns for winter and summer temperature, as Figure 8 demonstrates. Removing moving costs from the discrete choice model does not, however, cause estimates of MWTP for winter and summer temperature produced by the discrete choice model to mirror those produced by the hedonic model.

To investigate the impact of national versus city-specific labor markets, we estimate the discrete choice model derived from a Cobb-Douglas utility function (equation $9^{\prime}$ ), including only moving costs and city-specific fixed effects $\left(\delta_{j}\right)$ in the first stage. The second stage of estimation entails regressing city fixed effects on wages, housing prices, and amenities,

$$
\delta_{j}=\alpha_{Y} \ln Y_{j}-\alpha_{H} \ln \rho_{j}+\boldsymbol{A}_{j} \boldsymbol{\beta}+\xi_{j}
$$

which we assume vary only by city. In estimating equation (20), we replace $\ln Y_{j}$ by $(1-\tau) \lambda_{j}^{w}$ and $\ln \rho_{j}$ by $\lambda_{j}^{P}$, the same wage and housing price indices that are used in estimating the hedonic model. This imposes the assumption of national labor and housing markets on the discrete choice model. The resulting MWTP estimates are not, however, very different from those in Table 5: Mean MWTP for winter temperature is $\$ 344$ (s.e. $=\$ 72$ ); for summer temperature it is $-\$ 423$

\footnotetext{
${ }^{38}$ The two approaches also differ in their underlying econometric assumptions. The discrete choice approach adds a product-specific shock to the consumer's utility function $\left(\varepsilon_{\mathrm{ij}}\right)$. This "taste for product," which is absent from the hedonic model, leads the discrete choice approach to have undesirable properties in the context of models of product choice (Ackerberg and Rysman 2005; Bajari and Benkard 2003, 2004; Berry and Pakes 2001). For example, in standard random utility models, the demand for each product is strictly positive at every price (Bajari and Benkard $2003,2004)$. This can lead to very large values of consumer surplus associated with a product and overstate the welfare loss when a product is eliminated from the market. This is not, however, an issue in the current context.
} 
$($ s.e. $=\$ 125)$. The 95 percent confidence intervals therefore overlap with those produced by the base discrete choice model (M.2), which assumes city-specific labor and housing markets.

A third difference between the two approaches arises from the fact that the discrete choice model uses information on market shares in estimating model parameters, which the hedonic model does not. This can be seen by rewriting the equation for the second-stage of the discrete choice model (equation 20), following Bayer et al. (2007), as

$$
\delta_{j} / \alpha_{Y}+\left(\frac{\alpha_{H}}{\left.\alpha_{Y}\right)}\right) \ln \rho_{j}-\ln Y_{j}=\boldsymbol{A}_{j} \frac{\boldsymbol{\beta}}{\alpha_{Y}}+\xi_{j} / \alpha_{Y}
$$

where $\frac{\alpha_{H}}{\alpha_{Y}}$ is the share of income spent on housing. Equation (21) is similar to the hedonic equation, with the QOL index on the left-hand side adjusted by the city-specific fixed effect $\delta_{j}$. Given this adjustment, there is no reason why the discrete choice model should yield the same estimates of MWTP as the hedonic approach, provided $\delta_{j}$ varies across cities. Maximization of the likelihood function of the conditional logit model guarantees that each $\delta_{j}$ equates the sum of the probabilities that each household chooses city $j$ to the number of households in the sample that actually choose that city. Although $\delta_{j}$ will also be influenced by other variables that enter the first stage of estimation, $\delta_{j}$ will reflect the number of households living city $j$; under random sampling, this will be proportional to city population. ${ }^{39}$ The use of quantity (share) information should therefore cause discrete choice estimates of MWTP to differ from hedonic estimates.

Equation (21) helps explain why mean MWTP for winter temperature is higher under the discrete choice than the hedonic approach. The city-specific fixed effects from the first stage of the conditional logit model with moving costs (the $\left\{\delta_{j}\right\}$ in equation 20) are more highly positively correlated with winter than with summer temperature. This raises MWTP for winter temperature in the discrete choice model compared with MWTP from the hedonic model.

\section{Conclusions}

The goal of this paper is to compare the continuous hedonic and discrete choice approaches to valuing climate amenities-in particular, summer and winter temperatures. While previous comparisons of the two methods have focused on comparing mean MWTP (Cragg and Kahn 1997; Bayer et al. 2009) we have focused on comparing how MWTP for small changes in winter and summer temperatures vary with a household's current location. Preferences for temperature represent a classic case of taste sorting, and for the purposes of valuing climate policies, it is essential to measure how MWTP for temperature varies with geographic location.

\footnotetext{
${ }^{39}$ Specifically, the correlation between $\left\{\delta_{j}\right\}$ and city population is 0.71 .
} 
Simply put, the patterns of taste sorting produced by the two approaches are quite different. The discrete location choice model suggests that households who live in cities with warmer winters place a higher value on warmer winters than households who live in cities with colder winter temperatures, although there is variation across cities in MWTP holding temperature constant. The continuous hedonic approach using adjusted weights and local linear regression suggests the opposite: MWTP for an increase in winter temperature is higher for households living in the West North Central census division, where it is very cold, and in the Northeast US, than it is in Florida and Texas.

In terms of summer temperature, the discrete choice approach estimates that climatesensitive households in the South Atlantic census division and on the Pacific coast are willing to pay the most to lower summer temperature. Households in the West North Central division are willing to pay the least for cooler summers. In contrast, hedonic local linear regressions with adjusted weights suggest that MWTP for cooler summers is negatively correlated with temperature at current location: people on the Pacific coast and in the mountain states consider warmer summers to be a disamenity, but less so than people living in the South Atlantic, West South Central, and East South Central census divisions, who will bear the brunt of hotter summers under climate change (Karl et al. 2009).

There is also a difference in the mean MWTP across models. MWTP for warmer winters is lower, on average, in the hedonic model with adjusted weights than in the discrete choice case: when taste sorting is allowed, mean MWTP for a 1 degree increase in winter temperature is $\$ 175$ with a 95 percent confidence interval of $(\$ 124, \$ 203)$, whereas it is approximately $\$ 400$ in the discrete choice model (model M.2 of Table 5). Mean MWTP to avoid warmer summers is approximately the same in the hedonic model with adjusted weights as in the discrete choice model, approximately $\$ 500$ per degree.

These findings raise an obvious question: Why do results differ across models? Bayer et al. (2009) suggest that it is the inclusion of moving costs in the discrete choice model that causes their hedonic and discrete choice results to differ. Including moving costs in the discrete choice identifies the sorting patterns in this model, i.e., it causes MWTP for warmer winters to increase with winter temperature. However, removing moving costs does not result in the sorting patterns estimated using the hedonic model.

The hedonic and discrete choice approaches differ in other ways. The construction of hedonic QOL indices is based on national labor and housing market equations that assume that the returns to human capital and the marginal cost of housing characteristics are everywhere equal. The discrete choice approach, in contrast, treats each city as a separate market and allows 
variation in the returns to human capital and in the marginal price of dwelling characteristics across cities to identify household preferences. Imposing the assumption of national labor and housing markets on the discrete choice model does not, however, significantly alter estimates of mean MWTP for winter and summer temperature produced by that model.

A more important difference between the hedonic and discrete choice models is how they use information on prices v. quantities. In the hedonic model wages and housing prices adjust to clear the labor and housing markets as households and firms sort across cities. The discrete choice approach uses variation in wages and housing prices across cities to explain the location decisions of households, but it also uses information on the number of households selecting each city to estimate the model. The city-specific fixed effects estimated in the first stage of the discrete choice model equate the sum of the probabilities of choosing a city to the number of persons in the sample who choose the city. In a random sample, this will be proportional to city population. When city fixed effects are regressed on amenities in the second stage of estimation of the discrete choice model, population is implicitly used to estimate preferences. This is not the case for the hedonic model. We show, following Bayer et al. (2007), that the second stage of estimation of the discrete choice model, assuming national labor and housing markets, is similar to that of the hedonic model, with hedonic prices adjusted for city-specific fixed effects. There is therefore no reason why the two approaches should produce identical estimates of mean MWTP for city-specific amenities.

This raises another question: If the hedonic and discrete choice approaches yield different results, which approach yields the more reliable estimates of the value of climate amenities for use in evaluating climate policy? We believe that several considerations argue in favor of the discrete choice approach. As noted above, the discrete choice approach captures the stylized fact that the majority of households in the United States live in the same state in which the head of household was born. Informational and psychological frictions make households less than perfectly mobile. The discrete choice approach also makes use of spatial differences in labor and housing markets to identify household preferences, rather than assuming a national labor and housing market.

Finally, the discrete choice approach is more easily able to measure the impact of urban amenities on all household groups. The hedonic approach typically focuses on the preferences of prime-aged households, since a significant fraction of older households have no wage income. But climate benefits accrue to all households. In Sinha et al. (2018b) we present estimates of the discrete choice model for households headed by prime-aged adults, adults over 55, and all households with heads 16 years and older. Estimates of MWTP based on all households are approximately 40 percent greater than those based on the prime-aged sample. Older households 
place a higher value on warmer winters and cooler summers, and it is important to estimate these benefits. 


\section{References}

Ackerberg, D. A., and M. Rysman. 2005. Unobserved Product Differentiation in Discrete-Choice Models: Estimating Price Elasticities and Welfare Effects. RAND Journal of Economics 36 (4): 1-19.

Albouy, D. Y. 2012. Are Big Cities Bad Places to Live? Estimating Quality of Life across Metropolitan Areas. NBER Working Paper 14472. Cambridge, MA: National Bureau of Economic Research.

Albouy, D., W. Graf, R. Kellogg, and H. Wolff. 2016. Climate Amenities, Climate Change and American Quality of Life. Journal of the Association of Environmental and Resource Economists 3 (1): 205-46.

Bajari, P., and L. Benkard. 2003. Discrete Choice Models as Structural Models of Demand: Some Economic Implications of Common Approaches. Working paper. https://web.stanford.edu/ lanierb/research/al3-13-03.pdf.

—. 2004. Comparing Hedonic and Random Utility Models of Demand with an Application to PC's. Working paper. http://web.stanford.edu/ lanierb/research/Discrete_Choice_Models_WP.pdf.

— 2005. Demand Estimation with Heterogeneous Consumers and Unobserved Product Characteristics: A Hedonic Approach. Journal of Political Economy 113 (6): 1239-76.

Bajari, P., and M. Kahn. 2005. Estimating Housing Demand with an Application to Explaining Racial Segregation in Cities. Journal of Business and Economic Statistics 23 (1): 20-33.

Barreca, A., K. Clay, O. Deschenes, M. Greenstone, and J. S. Shapiro. 2016. Adapting to Climate Change: The Remarkable Decline in the US Temperature-Mortality Relationship over the Twentieth Century. Journal of Political Economy 124 (1): 105-59.

Bayer, P., F. Ferreira, and R. McMillan. 2007. A Unified Framework for Measuring Preferences for Schools and Neighborhoods. Journal of Political Economy 115 (4): 588-638.

Bayer, P., N. Keohane, and C. Timmins. 2009. Migration and Hedonic Valuation: The Case of Air Quality. Journal of Environmental Economics and Management 58: 1-14.

Berry, S. T., and P. A. Haile. 2010. Nonparametric Identification of Multinomial Choice Demand Models with Heterogeneous Consumers. Cowles Foundation Discussion Paper No. 1718. New Haven, CT: Cowles Foundation for Research in Economics, Yale University.

Berry, S., O. B. Linton, and A. Pakes. 2004. Limit Theorems for Estimating the Parameters of Differentiated Product Demand Systems. Review of Economic Studies 71 (3): 613-54.

Berry, S., and A. Pakes. 2001. The Pure Characteristics Discrete Choice Model with Application to Price Indices. Working paper. https://pdfs.semanticscholar.org/01fd/ce10c2ecc393badb424d47fde92b687a7115.pdf.

Bieri, D., N. Kuminoff, and J. Pope. 2013. National Expenditures on Local Amenities. Working paper. http://www.public.asu.edu/ nkuminof/BKP2.pdf.

Blomquist, G. C., M. C. Berger, and J. P. Hoehn. 1988. New Estimates of Quality of Life in Urban Areas. American Economic Review 78 (1): 89-107. 
Cragg, M., and M. Kahn. 1997. New Estimates of Climate Demand: Evidence from Location Choice. Journal of Urban Economics 42: 261-84.

-1999. Climate Consumption and Climate Pricing from 1940 to 1990. Regional Science and Urban Economics 29: 519-39.

Dahl, G. 2002. Mobility and the Return to Education: Testing a Roy Model with Multiple Markets. Econometrica 70 (6): 2367-3420.

Deschenes, O., and M. Greenstone. 2011. Climate Change, Mortality, and Adaptation: Evidence from Annual Fluctuations in Weather in the US. American Economic Journal: Applied Economics 3 (4): 152-85.

Fan, Q., A. Klaiber, and K. Fisher-Vanden. 2016. Does Extreme Weather Drive Interregional Brain Drain in the U.S.? Evidence from a Sorting Model. Land Economics 92 (2): 36388.

Graves, P., and P. Mueser. 1993. The Role of Equilibrium and Disequilibrium in Modeling Regional Growth and Decline: A Critical Reassessment. Journal of Regional Science 33 (1): 69-84.

Gyourko, J., and J. Tracy. 1991. The Structure of Local Public Finance and the Quality of Life. Journal of Political Economy 99 (4): 774-806.

Kahn, M. 2009. Urban Growth and Climate Change. Annual Review of Resource Economics 1: 333-50.

Karl, T. R., J. M. Melillo, and T. C. Peterson, eds. 2009. Global Climate Change Impacts in the United States. Cambridge, UK: Cambridge University Press.

Klaiber, H. A., and D. J. Phaneuf. 2009. Do Sorting and Heterogeneity Matter for Open Space Policy Analysis? An Empirical Comparison of Hedonic and Sorting Models. American Journal of Agricultural Economics 91 (5): 1312-18.

Li, Q., and J.S. Racine. 2007. Nonparametric Econometrics, Theory and Practice. Princeton: Princeton University Press.

McFadden, D. 1978. Modeling the Choice of Residential Location. In Spatial Interaction Theory and Planning Models, edited by A. Karlqvist, L. Lundquist, F. Snickars, and J. Weibull. Amsterdam: North Holland.

Murdock, J. 2006. Handling Unobserved Site Characteristics in Random Utility Models of Recreation Demand. Journal of Environmental Economics and Management 51: 1-25.

Nerella, S., and C. Bhat. 2004. Numerical Analysis of Effect of Sampling of Alternatives in Discrete Choice Models. Transportation Research Record: Journal of the Transportation Research Board 1894: 11-19.

Rappaport, J. 2007. Moving to Nice Weather. Regional Science and Urban Economics 47 (3): 375-98.

Revelt, D., and K. Train. 1999. Customer-Specific Taste Parameters and Mixed Logit. Working paper. Berkeley: University of California, Department of Economics.

Roback, J. 1982. Wages, Rents, and the Quality of Life. Journal of Political Economy 90 (6): 1257-78. 
Robinson, P. 1988. Root-n-Consistent Semiparametric Regression, Econometrica 56: 931-54.

Rosen, S. 1974. Hedonic Prices and Implicit Markets: Product Differentiation in Pure Competition. Journal of Political Economy 82 (1): 34-55.

Savageau, D., and R. D’Agostino. 2000. Places Rated Almanac: Millennium Edition. New York: Hungry Minds.

Schlenker, W., and M. Roberts. 2009. Nonlinear Temperature Effects Indicate Severe Damages to US Crop Yields under Climate Change. Proceedings of the National Academy of Sciences 106 (37): 15594-98.

Sinha, P., M.C. Caulkins and M. Cropper. 2018a. Do Discrete Choice Approaches to Valuing Urban Amenities Yield Different Results Than Hedonic Models? Discussion paper 1802. Washington, DC: Resources for the Future.

- 2018b. Household Location Decisions and the Value of Climate Amenities. Journal of Environmental Economics and Management. 92: 608-637.

Wong, M. Forthcoming. A Tractable Framework to Relate Marginal Willingness-to-Pay in Hedonic and Discrete Choice Models. Journal of Housing Economics. 
Table 1. Descriptive Statistics of Household Characteristics

\begin{tabular}{|c|c|c|c|c|c|c|c|}
\hline \multirow[b]{2}{*}{ Variable } & \multirow[b]{2}{*}{ Description } & \multicolumn{2}{|c|}{$\begin{array}{l}\text { Full sample } \\
\text { (N: 54,008) }\end{array}$} & \multicolumn{2}{|c|}{$\begin{array}{l}\text { Prime-aged } \\
(N: 33,180) \\
\end{array}$} & \multicolumn{2}{|c|}{$\begin{array}{l}\text { Greater than } 55 \\
(N: 17,643)\end{array}$} \\
\hline & & Mean & Std. dev. & Mean & Std. dev. & Mean & Std. dev. \\
\hline $\begin{array}{l}\text { Age of household head } \\
\text { (mean) }\end{array}$ & Age & 49.11 & 17.03 & 40.79 & 8.20 & 69.50 & 9.41 \\
\hline $\begin{array}{l}\text { Gender of household head } \\
\text { (proportion) }\end{array}$ & Male & 63.93 & & 67.02 & & 60.60 & \\
\hline $\begin{array}{l}\text { Marital status of household } \\
\text { head (proportion) }\end{array}$ & Married & 52.22 & & 55.43 & & 50.99 & \\
\hline \multirow{3}{*}{$\begin{array}{l}\text { Race of household head } \\
\text { (proportions) }\end{array}$} & White & 82.70 & & 81.13 & & 87.03 & \\
\hline & Black & 13.11 & & 13.97 & & 10.98 & \\
\hline & Other & 4.20 & & 4.91 & & 1.99 & \\
\hline \multirow{5}{*}{$\begin{array}{l}\text { Education of household } \\
\text { head (proportions) }\end{array}$} & No high school & 12.86 & & 7.56 & & 23.09 & \\
\hline & High school & 25.96 & & 24.06 & & 29.71 & \\
\hline & Some college & 30.89 & & 33.73 & & 23.65 & \\
\hline & College graduate & 19.33 & & 22.67 & & 12.95 & \\
\hline & Postgraduate education & 10.96 & & 11.99 & & 10.62 & \\
\hline \multirow{3}{*}{$\begin{array}{l}\text { Household head movement } \\
\text { from place of birth } \\
\text { (proportions) }\end{array}$} & Left state of birth & 42.65 & & 40.99 & & 47.32 & \\
\hline & Left census division of birth & 32.78 & & 31.28 & & 36.86 & \\
\hline & Left census region of birth & 26.55 & & 24.98 & & 30.85 & \\
\hline $\begin{array}{l}\text { Household wage earnings } \\
\text { (mean) }\end{array}$ & $\begin{array}{l}\text { Sum of the wage earnings of all } \\
\text { household members }\end{array}$ & $\$ 49,960$ & $\$ 54,508$ & $\$ 64,098$ & $\$ 55,106$ & $\$ 26,307$ & $\$ 47,544$ \\
\hline $\begin{array}{l}\text { Household wage earnings } \\
\text { (proportion) }\end{array}$ & $\begin{array}{l}\text { Households with zero wage } \\
\text { earnings }\end{array}$ & 16.75 & & 2.23 & & 46.94 & \\
\hline
\end{tabular}




\begin{tabular}{|c|c|c|c|c|c|c|c|}
\hline \multirow[b]{2}{*}{ Variable } & \multirow[b]{2}{*}{ Description } & \multicolumn{2}{|c|}{$\begin{array}{l}\text { Full sample } \\
(N: 54,008) \\
\end{array}$} & \multicolumn{2}{|c|}{$\begin{array}{l}\text { Prime-aged } \\
(N: 33,180) \\
\end{array}$} & \multicolumn{2}{|c|}{$\begin{array}{c}\text { Greater than } 55 \\
(N: 17,643)\end{array}$} \\
\hline & & Mean & Std. dev. & Mean & Std. dev. & Mean & Std. dev. \\
\hline $\begin{array}{l}\text { Total household income } \\
\text { (mean) }\end{array}$ & $\begin{array}{l}\text { Sum of wage, business, and farm } \\
\text { incomes and income from other } \\
\text { sources of all household members }\end{array}$ & $\$ 63,312$ & $\$ 58,671$ & $\$ 69,161$ & $\$ 59,723$ & $\$ 57,294$ & $\$ 58,615$ \\
\hline $\begin{array}{l}\text { Household annual housing } \\
\text { expenditures (mean) }\end{array}$ & $\begin{array}{l}\text { Sum of monthly mortgage } \\
\text { payment or rent, cost of utilities, } \\
\text { insurance, and property taxes }\end{array}$ & $\$ 15,556$ & $\$ 9,082$ & $\$ 16,193$ & $\$ 9,437$ & $\$ 15,481$ & $\$ 8,560$ \\
\hline \multirow{3}{*}{$\begin{array}{l}\text { Size of household } \\
\text { (proportions) }\end{array}$} & 1 member & 26.16 & & 21.05 & & 36.03 & \\
\hline & 2 members & 34.69 & & 27.35 & & 47.68 & \\
\hline & 3 or more members & 39.15 & & 51.59 & & 16.28 & \\
\hline
\end{tabular}

${ }^{a}$ Income from other sources would include Social Security income; welfare (public assistance) income; Supplementary Security Income; interest, dividend, and rental income; retirement income; and other income. 
Table 2. Descriptive Statistics of Amenity Variables

\begin{tabular}{|c|c|c|c|c|c|c|}
\hline Variable & $N$ & Mean & Std. dev. & Minimum & Maximum & Median \\
\hline Avg. winter temperature $\left({ }^{\circ} \mathrm{F}\right)$ & 284 & 37.339 & 12.158 & 9.442 & 67.922 & 34.996 \\
\hline Avg. summer temperature $\left({ }^{\circ} \mathrm{F}\right)$ & 284 & 73.309 & 5.817 & 60.848 & 89.733 & 72.517 \\
\hline Annual snowfall (inches) & 284 & 20.360 & 21.366 & 0.000 & 84.050 & 18.050 \\
\hline Summer precipitation (inches) & 284 & 10.966 & 5.057 & 0.440 & 23.300 & 11.932 \\
\hline July relative humidity (\%) & 284 & 66.246 & 10.891 & 22.500 & 78.000 & 70.500 \\
\hline Annual sunshine (\% of possible sunshine in 24 hours) & 284 & 60.764 & 8.323 & 43.000 & 78.000 & 58.000 \\
\hline Avg. elevation (miles) & 284 & 0.197 & 0.273 & 0.000 & 1.620 & 0.130 \\
\hline Distance to coast (miles) & 284 & 141.096 & 169.592 & 0.009 & 824.451 & 91.025 \\
\hline Visibility $>10$ miles (\% of hours) & 284 & 46.053 & 19.541 & 5.000 & 85.500 & 45.500 \\
\hline Mean $\mathrm{PM}_{2.5}$ (micrograms/cubic meter) & 284 & 12.829 & 2.884 & 5.382 & 19.535 & 12.818 \\
\hline Population density (persons per square mile) & 284 & 471.767 & 983.041 & 5.400 & $13,043.600$ & 259.050 \\
\hline Violent crime rate (number of violent crimes per 1,000 persons) & 284 & 4.560 & 2.214 & 0.069 & 12.330 & 4.349 \\
\hline Park area (square miles) & 284 & 192.908 & 584.303 & 0.000 & $5,477.564$ & 24.893 \\
\hline Transportation score & 284 & 50.370 & 29.181 & 0.000 & 100.000 & 50.280 \\
\hline Education score & 284 & 51.230 & 29.322 & 0.000 & 100.000 & 51.130 \\
\hline Arts score & 284 & 51.137 & 29.055 & 0.000 & 100.000 & 51.140 \\
\hline Healthcare score & 284 & 49.201 & 28.657 & 0.000 & 98.300 & 49.430 \\
\hline Recreation score & 284 & 53.342 & 28.386 & 0.000 & 100.000 & 54.245 \\
\hline
\end{tabular}


Table 3. Hedonic Wage, Housing Cost, and Quality of Life Regressions

\begin{tabular}{|c|c|c|c|c|}
\hline & $\begin{array}{c}\text { Wage } \\
\text { regression } \\
(1)\end{array}$ & $\begin{array}{l}\text { Housing cost } \\
\text { regression } \\
\text { (2) }\end{array}$ & $\begin{array}{c}\text { QOL regression } \\
\text { Traditional Weights } \\
\text { (3) }\end{array}$ & $\begin{array}{l}\text { QOL regression } \\
\text { Adjusted weights } \\
\text { (4) }\end{array}$ \\
\hline Variable & $\begin{array}{c}\text { Coef. } \\
\text { (Std. err.) }\end{array}$ & $\begin{array}{c}\text { Coef. } \\
\text { (Std. err.) }\end{array}$ & $\begin{array}{c}\text { Coef. } \\
\text { (Std. err.) }\end{array}$ & $\begin{array}{c}\text { Coef. } \\
\text { (Std. err.) }\end{array}$ \\
\hline Avg. winter temperature & $\begin{array}{l}-0.0030 \\
(0.0008)\end{array}$ & $\begin{array}{l}-0.0001 \\
(0.0020)\end{array}$ & $\begin{array}{c}0.0030 \\
(0.0006)\end{array}$ & $\begin{array}{c}0.0015 \\
(0.0005)\end{array}$ \\
\hline Avg. summer temperature & $\begin{array}{l}-0.0010 \\
(0.0015)\end{array}$ & $\begin{array}{l}-0.0172 \\
(0.0040)\end{array}$ & $\begin{array}{l}-0.0033 \\
(0.0010)\end{array}$ & $\begin{array}{l}-0.0052 \\
(0.0009)\end{array}$ \\
\hline July humidity & $\begin{array}{l}-0.0007 \\
(0.0007)\end{array}$ & $\begin{array}{c}0.0020 \\
(0.0016)\end{array}$ & $\begin{array}{c}0.0012 \\
(0.0005)\end{array}$ & $\begin{array}{c}0.0010 \\
(0.0003)\end{array}$ \\
\hline Annual snowfall & $\begin{array}{l}-0.0010 \\
(0.0003)\end{array}$ & $\begin{array}{l}-0.0022 \\
(0.0007)\end{array}$ & $\begin{array}{c}0.0004 \\
(0.0002)\end{array}$ & $\begin{array}{l}-0.0002 \\
(0.0002)\end{array}$ \\
\hline Ln(summer precipitation) & $\begin{array}{l}-0.0247 \\
(0.0111)\end{array}$ & $\begin{array}{l}-0.0475 \\
(0.0283)\end{array}$ & $\begin{array}{c}0.0128 \\
(0.0080)\end{array}$ & $\begin{array}{l}-0.0031 \\
(0.0067)\end{array}$ \\
\hline Annual sunshine & $\begin{array}{c}0.0004 \\
(0.0009)\end{array}$ & $\begin{array}{c}0.0089 \\
(0.0022)\end{array}$ & $\begin{array}{c}0.0019 \\
(0.0006)\end{array}$ & $\begin{array}{c}0.0028 \\
(0.0005)\end{array}$ \\
\hline No. of obs. (MSAs) & 284 & 284 & 284 & 284 \\
\hline Adjusted $R$-squared & 0.71 & 0.74 & 0.50 & 0.59 \\
\hline
\end{tabular}

Note: Columns (1) and (2) present the coefficients of the climate amenities when $\lambda^{W}$ (col. 1) and $\lambda^{P}$ (col. 2) are regressed on the amenities in Table 2. Column (3) and (4) report the coefficients on climate amenities when the QOL index formed using traditional weights (col. 3) and adjusted weights (col. 4) are regressed on the amenities in Table 2. Appendix A.3 reports the complete set of regression coefficients. 
Table 4. Marginal Willingness to Pay for Climate Amenities: Hedonic Models, Heterogeneous Tastes

\begin{tabular}{|c|c|c|c|c|c|c|c|c|c|c|c|c|}
\hline \multirow[b]{2}{*}{ Weights } & \multirow[b]{2}{*}{ Bandwidth } & \multicolumn{4}{|c|}{ Winter temperature } & \multicolumn{4}{|c|}{ Summer temperature } & \multicolumn{3}{|c|}{ Correlations } \\
\hline & & Mean & $\begin{array}{l}\text { Std. } \\
\text { dev. }\end{array}$ & $\begin{array}{c}\text { 10th } \\
\text { pctile }\end{array}$ & $\begin{array}{l}\text { 90th } \\
\text { pctile }\end{array}$ & Mean & $\begin{array}{l}\text { Std. } \\
\text { dev. }\end{array}$ & $\begin{array}{l}\text { 10th } \\
\text { pctile }\end{array}$ & $\begin{array}{l}\text { 90th } \\
\text { pctile }\end{array}$ & $\begin{array}{c}\text { WT } \\
\text { MWTP, ST } \\
\text { MWTP }\end{array}$ & $\begin{array}{c}\text { WT, } \\
\text { WT } \\
\text { MWTP }\end{array}$ & $\begin{array}{c}\text { ST, } \\
\text { ST } \\
\text { MWTP }\end{array}$ \\
\hline Traditional & 0.4 & $\$ 215$ & $\$ 94$ & 89 & 337 & -346 & 327 & -780 & -54 & -0.02 & 0.13 & -0.46 \\
\hline Traditional & 0.5 & $\$ 207$ & $\$ 58$ & 136 & 281 & -329 & 214 & -701 & -136 & -0.11 & 0.16 & -0.48 \\
\hline Traditional & 0.8 & $\$ 189$ & $\$ 25$ & 158 & 222 & -261 & 74 & -371 & -194 & -0.30 & 0.07 & -0.56 \\
\hline Traditional & 0.9 & $\$ 185$ & $\$ 21$ & 160 & 211 & -243 & 54 & -315 & -196 & -0.34 & 0.04 & -0.57 \\
\hline Adjusted & 0.4 & $\$ 203$ & $\$ 123$ & 39 & 293 & -573 & 290 & -889 & -326 & -0.12 & -0.09 & -0.41 \\
\hline Adjusted & 0.5 & $\$ 189$ & $\$ 96$ & 61 & 262 & -558 & 233 & -790 & -376 & -0.09 & -0.19 & -0.46 \\
\hline
\end{tabular}

Note: The mean MWTPs reported here are weighted by MSA population. The standard deviations are standard deviations in MWTP from the mean. All figures, except correlations, are reported in dollars. 
Table 5. Marginal Willingness to Pay for Climate Amenities: Mixed Logit Models

\begin{tabular}{|c|c|c|c|c|c|c|c|c|}
\hline Panel A: 1st stage estimates & \multicolumn{2}{|c|}{$\begin{array}{l}\text { M.1: No tax } \\
\text { adjustments }\end{array}$} & \multicolumn{2}{|c|}{$\begin{array}{l}\text { M.2: With tax } \\
\text { adjustments }\end{array}$} & \multicolumn{2}{|c|}{$\begin{array}{l}\text { M.3: No tax } \\
\text { adjustments + Omit } \\
\text { moving costs }\end{array}$} & \multicolumn{2}{|c|}{$\begin{array}{l}\text { M.4: With tax } \\
\text { adjustments + } \\
\text { omit moving costs }\end{array}$} \\
\hline Variable & $\begin{array}{c}\text { Coef. } \\
\text { (Std. err.) }\end{array}$ & & $\begin{array}{c}\text { Coef. } \\
\text { (Std. err.) }\end{array}$ & & $\begin{array}{c}\text { Coef. } \\
\text { (Std. err.) }\end{array}$ & & $\begin{array}{c}\text { Coef. } \\
\text { (Std. err.) }\end{array}$ & \\
\hline Std. dev.: avg. winter temperature & $\begin{array}{c}0.0588 \\
(0.0026)\end{array}$ & & $\begin{array}{c}0.0592 \\
(0.0026)\end{array}$ & & $\begin{array}{c}0.0011 \\
(0.0128)\end{array}$ & & $\begin{array}{c}0.0032 \\
(0.0097)\end{array}$ & \\
\hline Std. dev.: avg. summer temperature & $\begin{array}{c}0.0592 \\
(0.0068)\end{array}$ & & $\begin{array}{c}0.0612 \\
(0.0066)\end{array}$ & & $\begin{array}{c}0.0352 \\
(0.0215)\end{array}$ & & $\begin{array}{c}0.0525 \\
(0.0174)\end{array}$ & \\
\hline Correlation coefficient & $\begin{array}{l}-0.6893 \\
(0.0827)\end{array}$ & & $\begin{array}{l}-0.6993 \\
(0.0776)\end{array}$ & & $\begin{array}{c}0.8614 \\
(0.2756)\end{array}$ & & $\begin{array}{l}-0.9433 \\
(0.1297)\end{array}$ & \\
\hline Panel B: 2nd stage estimates & & & & & & & & \\
\hline Variable & $\begin{array}{c}\text { Coef } \\
\text { (Std. err.) }\end{array}$ & $\begin{array}{c}\text { MWTP } \\
\text { (Std. err.) }\end{array}$ & $\begin{array}{c}\text { Coef } \\
\text { (Std. err.) }\end{array}$ & $\begin{array}{c}\text { MWTP } \\
\text { (Std. err.) }\end{array}$ & $\begin{array}{c}\text { Coef } \\
\text { (Std. err.) }\end{array}$ & $\begin{array}{c}\text { MWTP } \\
\text { (Std. err.) }\end{array}$ & $\begin{array}{c}\text { Coef } \\
\text { (Std. err.) }\end{array}$ & $\begin{array}{c}\text { MWTP } \\
\text { (Std. err.) }\end{array}$ \\
\hline Mean: avg. winter temperature & $\begin{array}{c}0.0209 \\
(0.0058)\end{array}$ & $\begin{array}{l}\$ 518 \\
(\$ 144)\end{array}$ & $\begin{array}{c}0.0210 \\
(0.0057)\end{array}$ & $\begin{array}{c}\$ 382 \\
(\$ 104)\end{array}$ & $\begin{array}{c}0.0184 \\
(0.0055)\end{array}$ & $\begin{array}{c}\$ 491 \\
(\$ 146)\end{array}$ & $\begin{array}{c}0.0171 \\
(0.0055)\end{array}$ & $\begin{array}{l}\$ 326 \\
(\$ 104)\end{array}$ \\
\hline Mean: avg. summer temperature & $\begin{array}{l}-0.0253 \\
(0.0100)\end{array}$ & $\begin{array}{l}-\$ 627 \\
(\$ 249)\end{array}$ & $\begin{array}{l}-0.0286 \\
(0.0098)\end{array}$ & $\begin{array}{l}-\$ 522 \\
(\$ 180)\end{array}$ & $\begin{array}{l}-0.0145 \\
(0.0108)\end{array}$ & $\begin{array}{l}-\$ 386 \\
(\$ 288)\end{array}$ & $\begin{array}{l}-0.0178 \\
(0.0110)\end{array}$ & $\begin{array}{l}-\$ 339 \\
(\$ 209)\end{array}$ \\
\hline
\end{tabular}

Note: These models include all amenities listed in Table 2. Coefficients of other amenities are reported in Table A.5. 
Figure 1A. Impact of Winter Temperature on QOL Index (Adjusted Weights, Only WT Nonparametric)

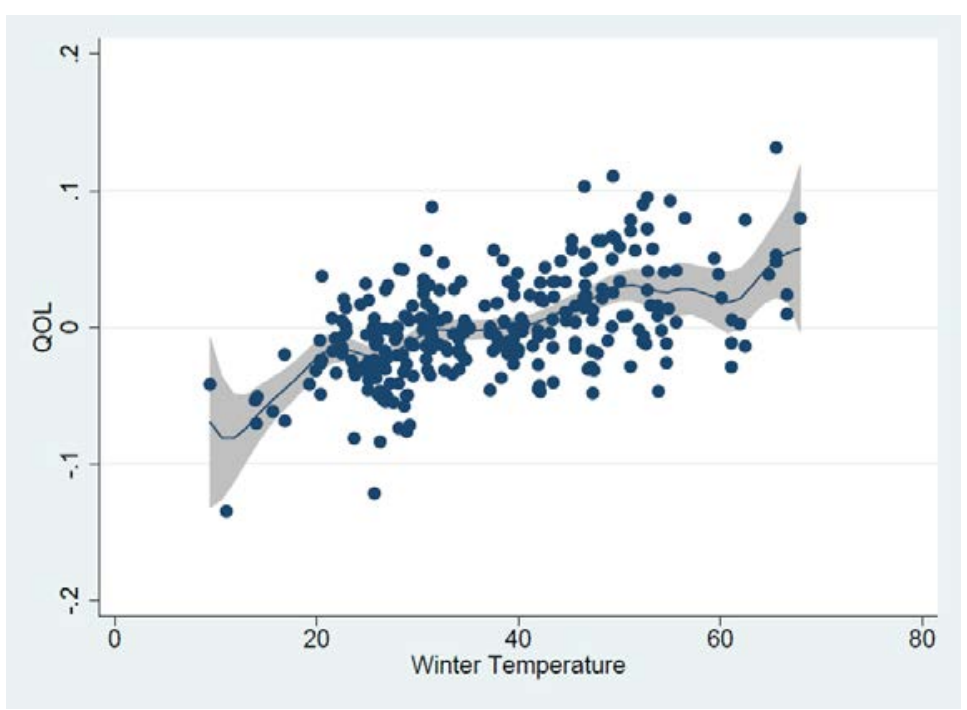

Figure 1B. Impact of Summer Temperature on QOL Index (Adjusted Weights, Only ST Nonparametric)

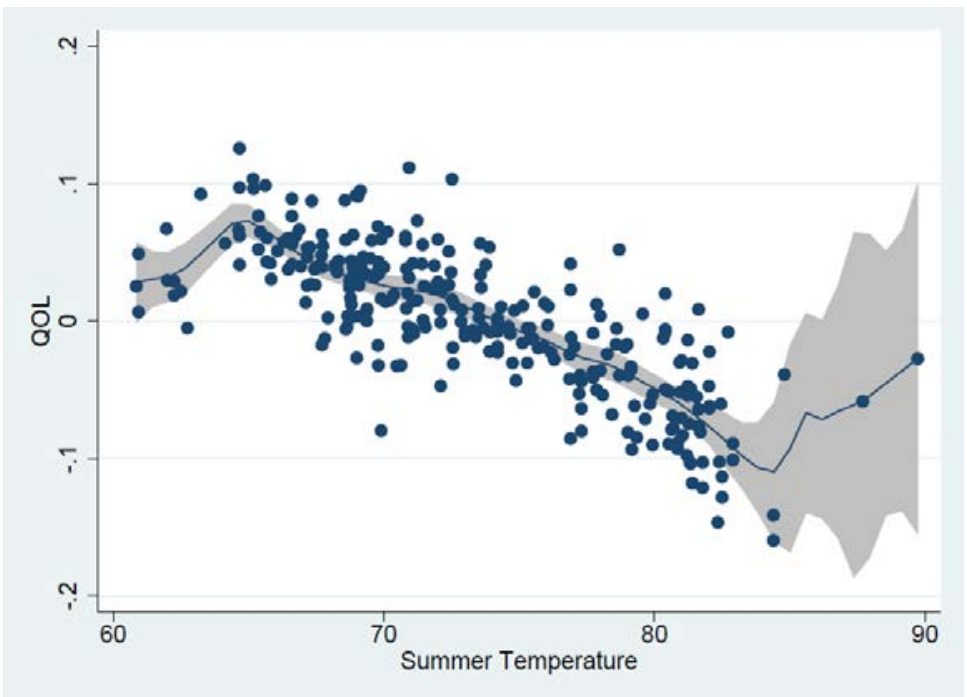


Figure 2A. Impact of Winter Temperature on QOL Index (Traditional Weights, Only WT Nonparametric)

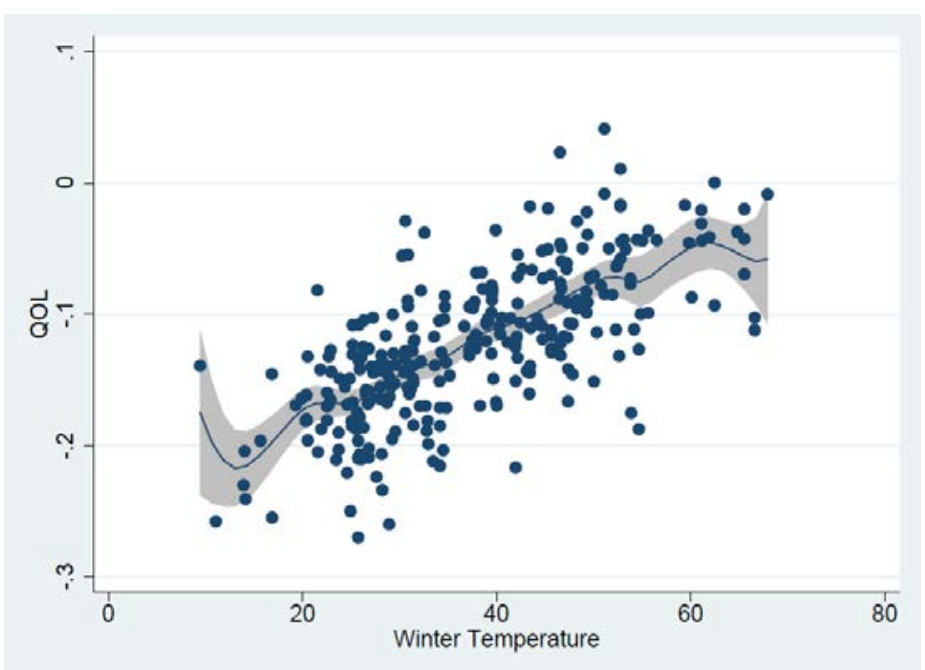

Figure 2B. Impact of Summer Temperature on QOL Index (Traditional Weights, Only ST Nonparametric)

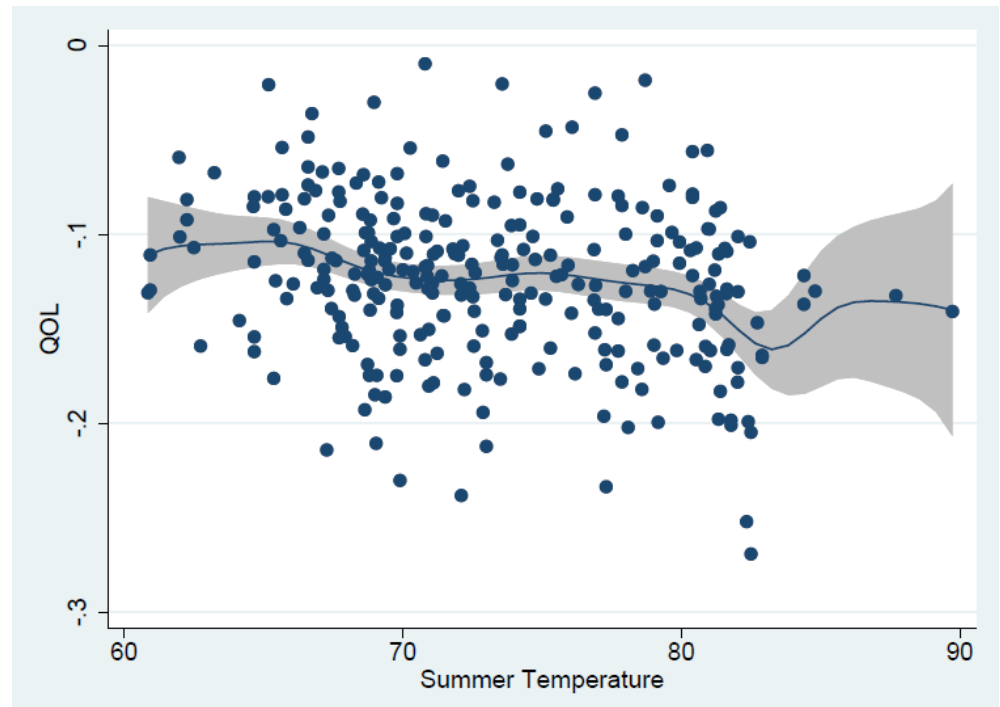


Figure 3A. MWTP for Winter Temperature as a Function of Winter Temperature

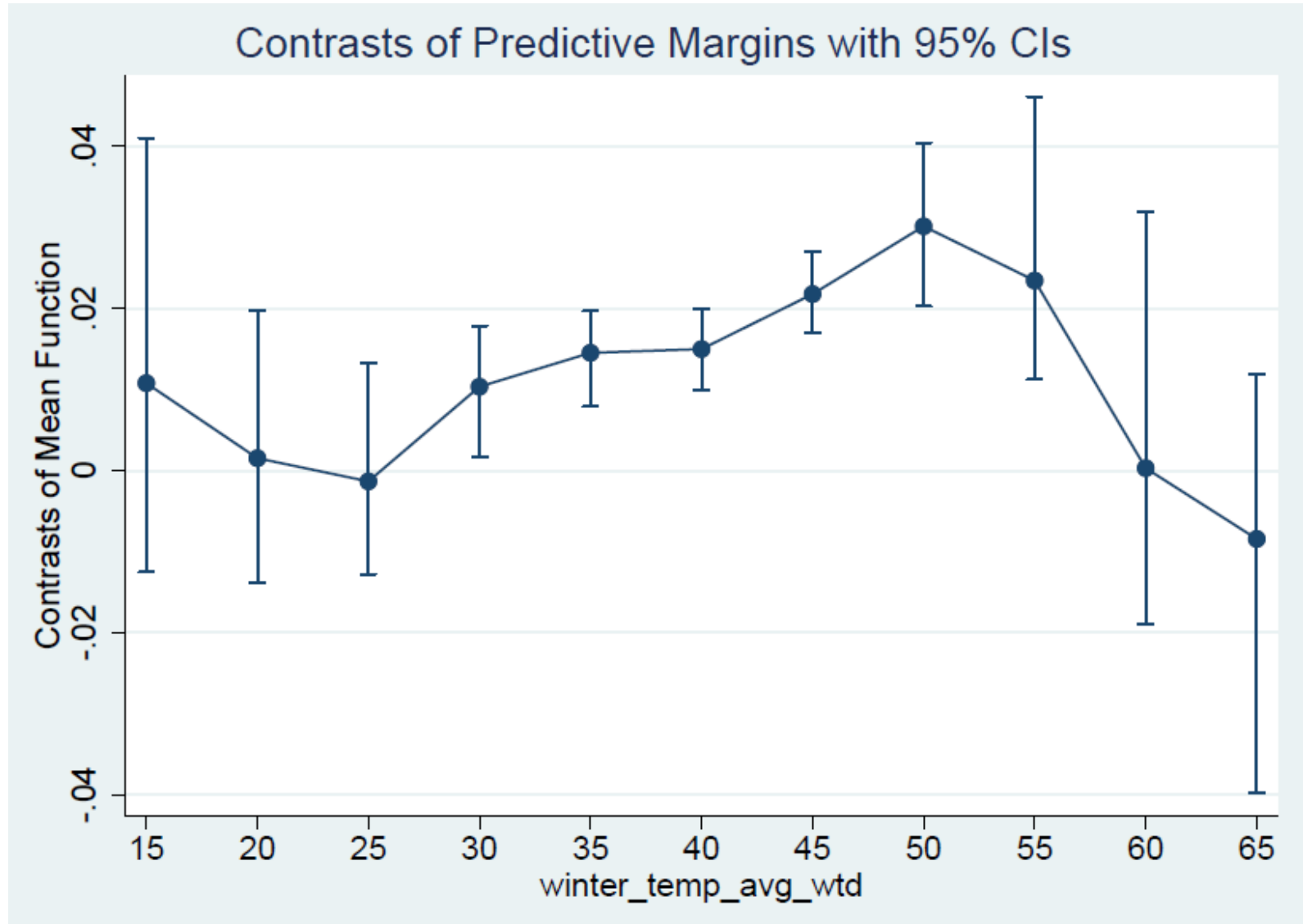

Note: The point estimates in this graph represent the proportion of income, measured on the $\mathrm{Y}$ axis. that would be given up for a 5 degree increase in temperature to the number shown on the $X$-axis. For example, increasing winter temperature from 10 to 15 degrees is worth $1 \%$ of income (.01), although the error bars on the graph indicate that this coefficient is not significantly different from zero. An increase in mean winter temperature from 15 to 20 degrees has a point estimate of 0 . These effects reported in the graph are averaged across all values of summer temperature. 
Figure 3B. MWTP for Summer Temperature as a Function of Summer Temperature

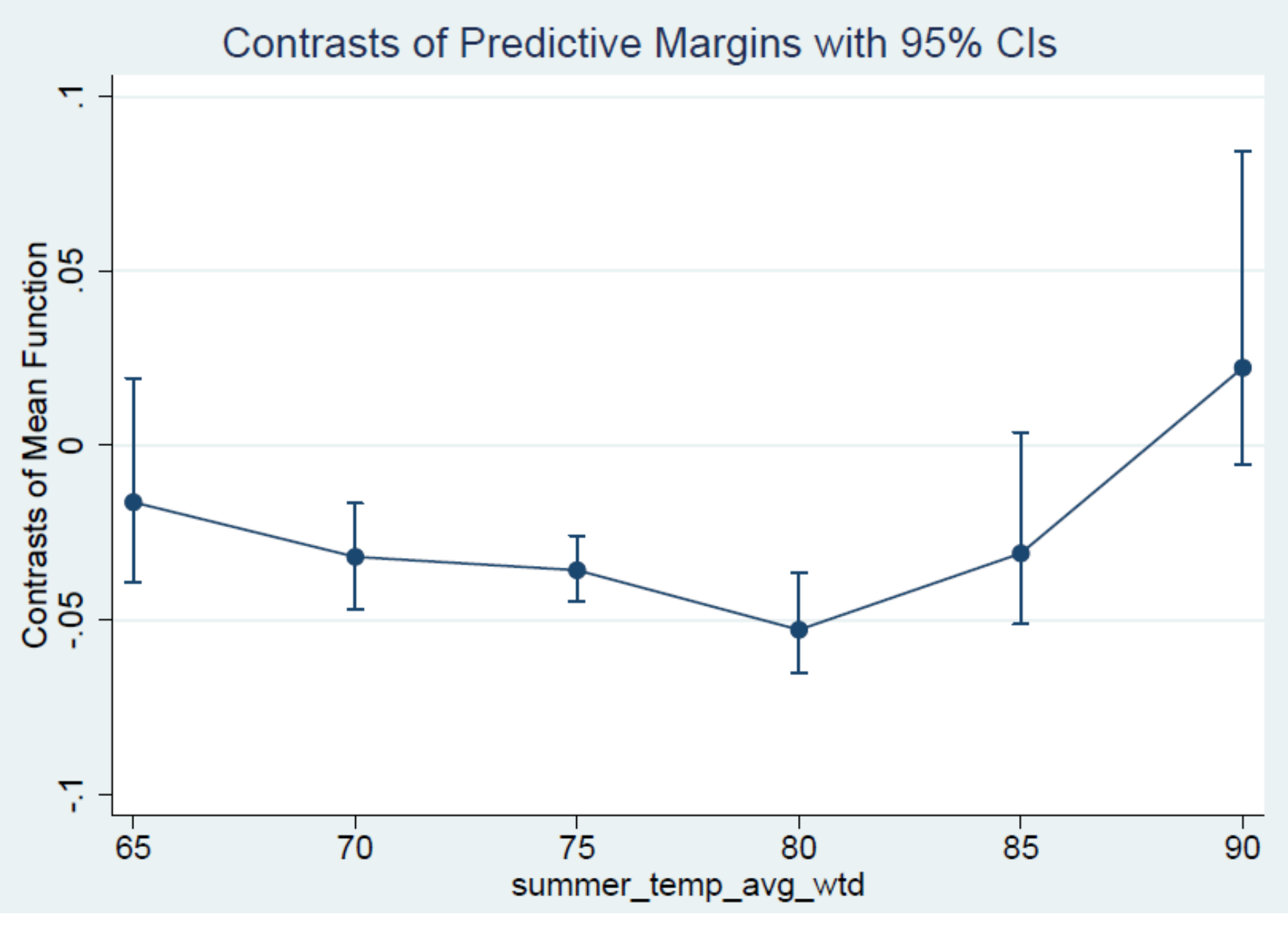

Note: The point estimates in this graph represent the proportion of income, measured on the $Y$ axis. that would be given up for a 5 degree increase in temperature to the value on the $X$-axis. For example, increasing summer temperature from 60 to 65 degrees is worth $-2 \%$ of income ( $2 \%$ of income would be given up to avoid this change), although the error bars on the graph indicate that this coefficient is not significantly different from zero. The value of avoiding an increase in mean summer temperature from 65 to 70 is approximately $3 \%$ of income. The effects reported in the graph are averaged across all values of winter temperature. 
Figure 4. Marginal Willingness to Pay for Winter Temperature by Metropolitan Area, Local Linear Hedonic Model, Adjusted Weights (bandwidth $=0.7$ )

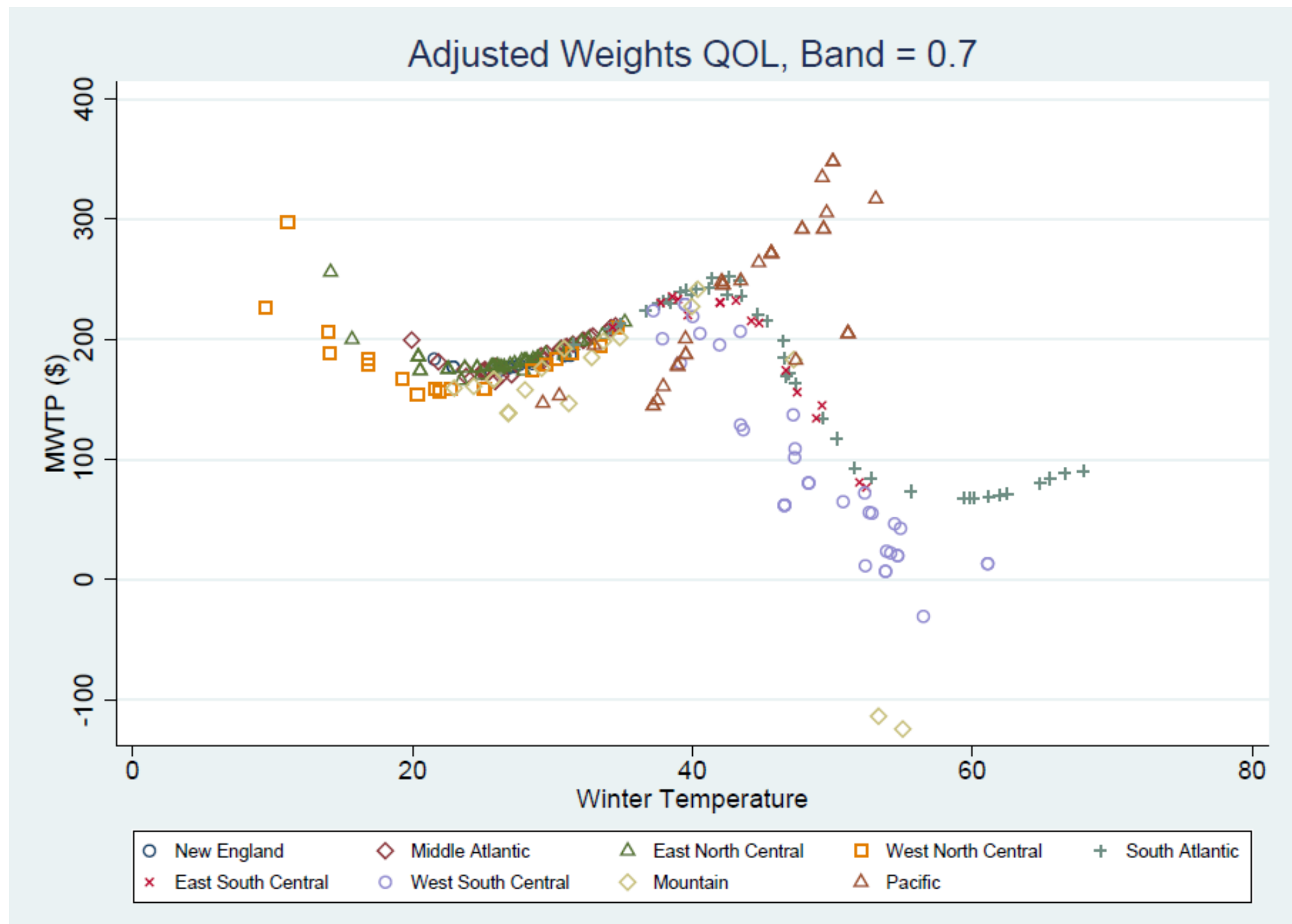


Figure 5. Marginal Willingness to Pay for Summer Temperature by Metropolitan Area, Local Linear Hedonic Model, Adjusted Weights (bandwidth $=0.7$ )

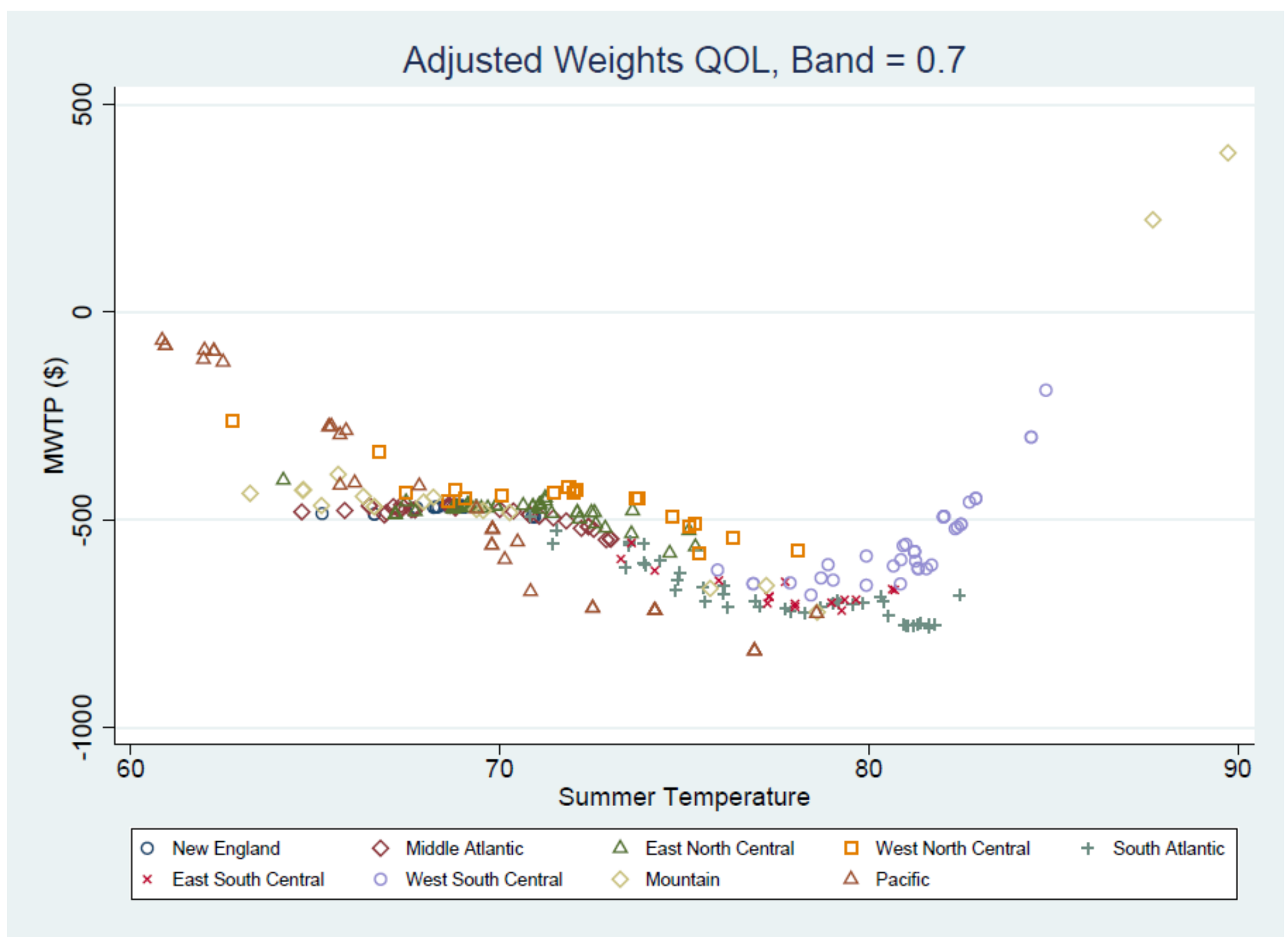


Figure 6A. Marginal Willingness to Pay for Winter Temperature by Metropolitan Area, Discrete Choice Model, No Tax Adjustments (Model M.1)

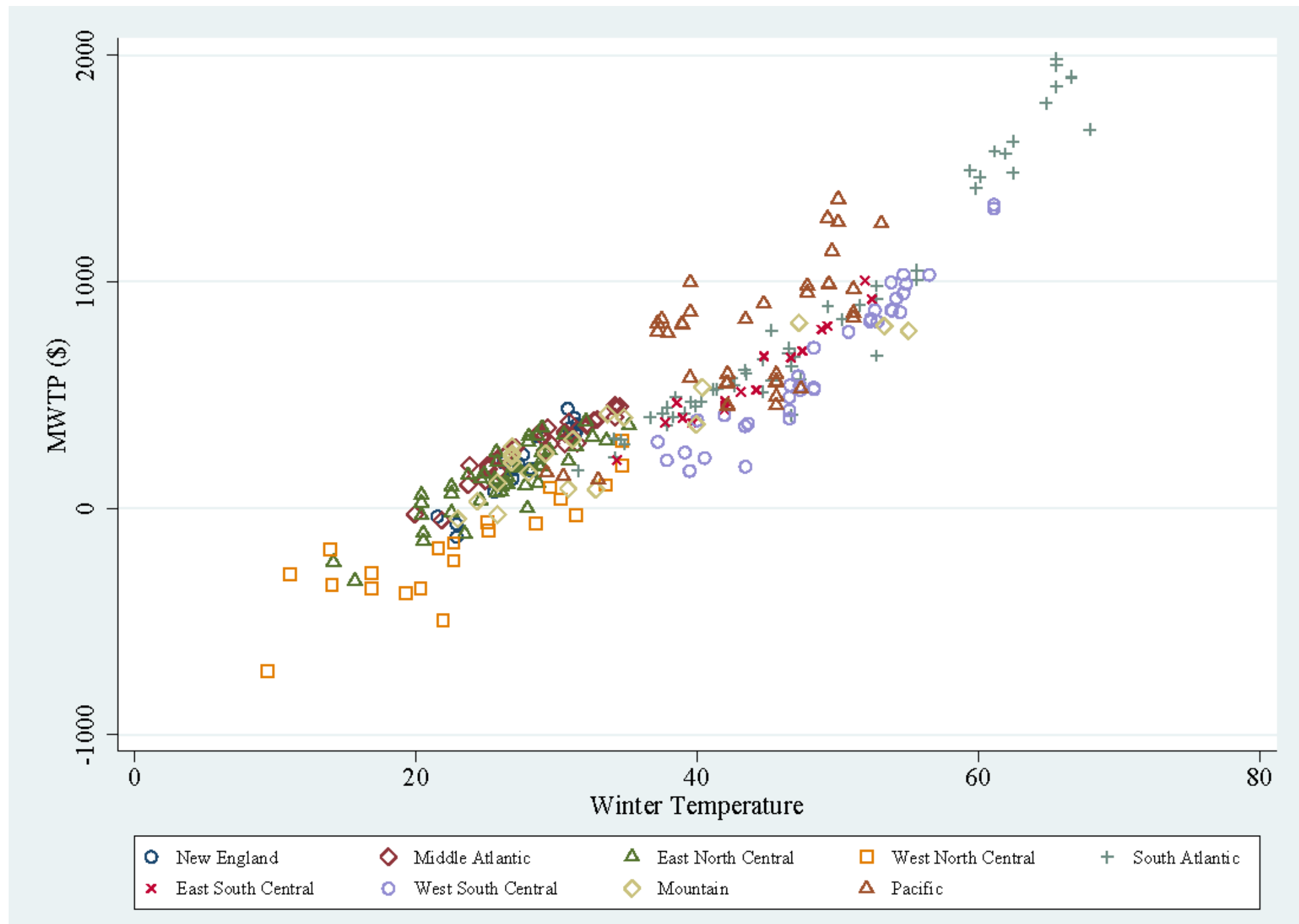


Figure 6B. Marginal Willingness to Pay for Winter Temperature by Metropolitan Area, Discrete Choice Model, With Tax Adjustments (Model M.2)

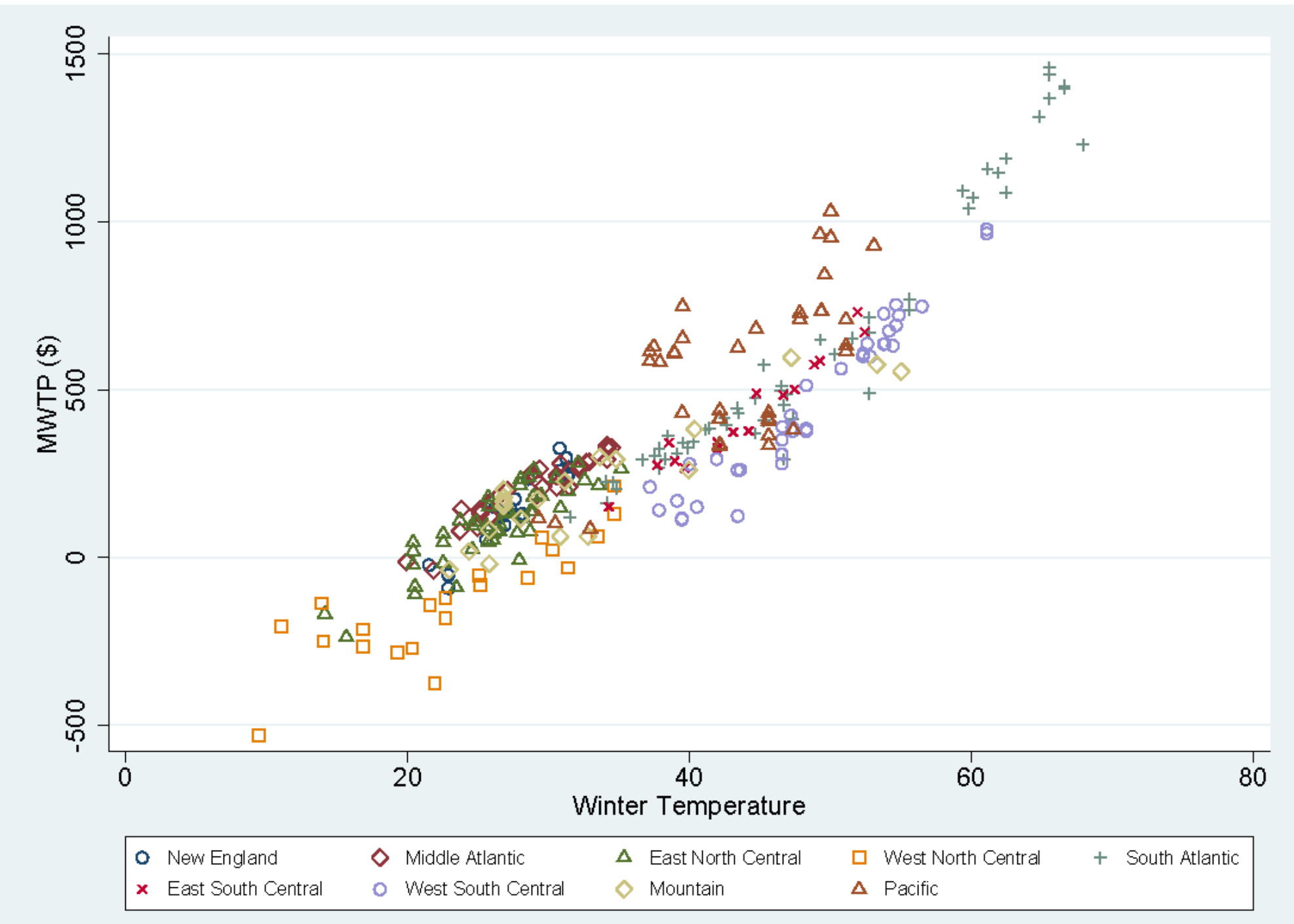


Figure 7A. Marginal Willingness to Pay for Summer Temperature by Metropolitan Area, Discrete Choice, No Tax Adjustments (Model M.1)

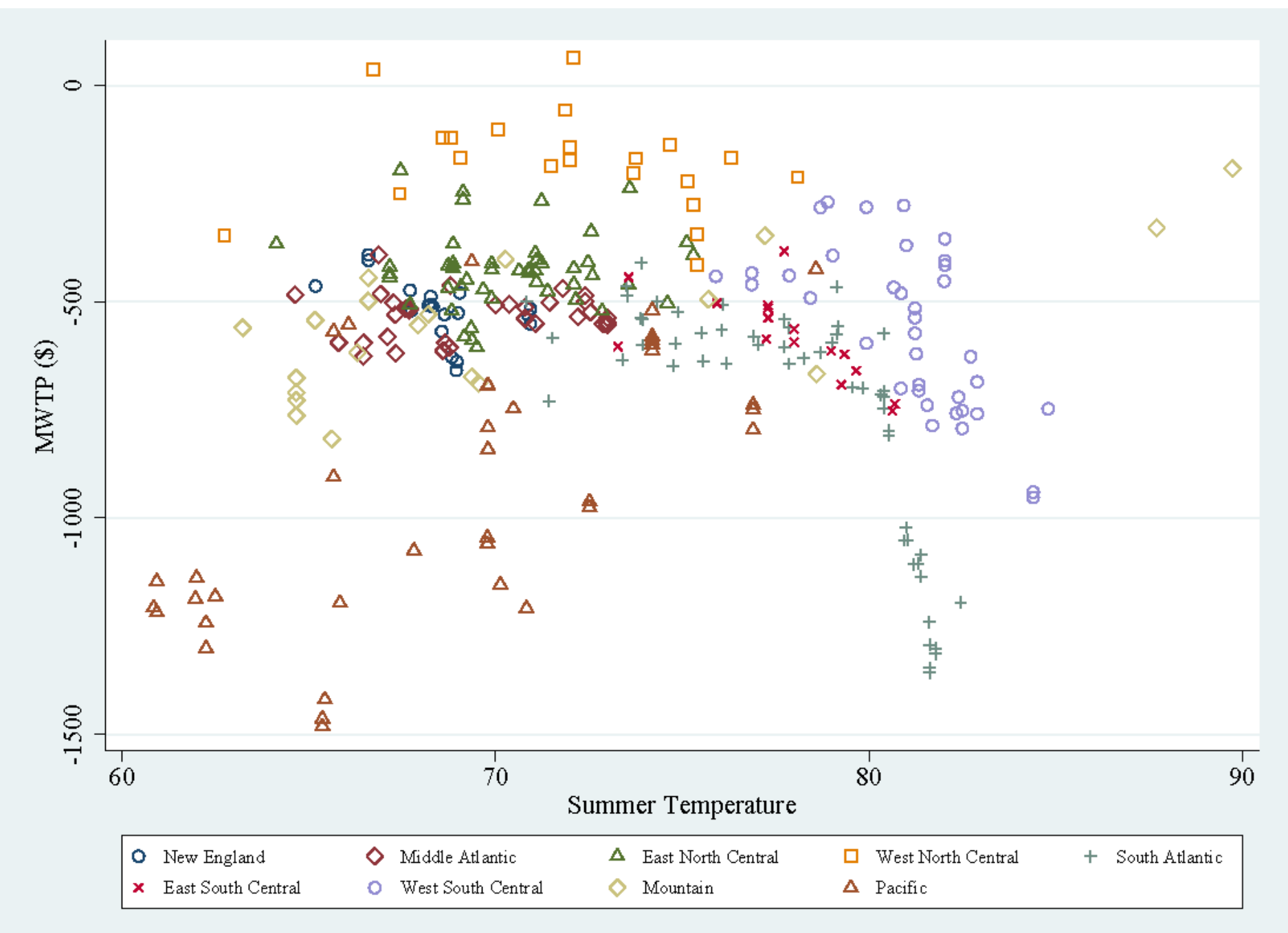


Figure 7B. Marginal Willingness to Pay for Summer Temperature by Metropolitan Area, Discrete Choice Model, With Tax Adjustments (Model M.2)

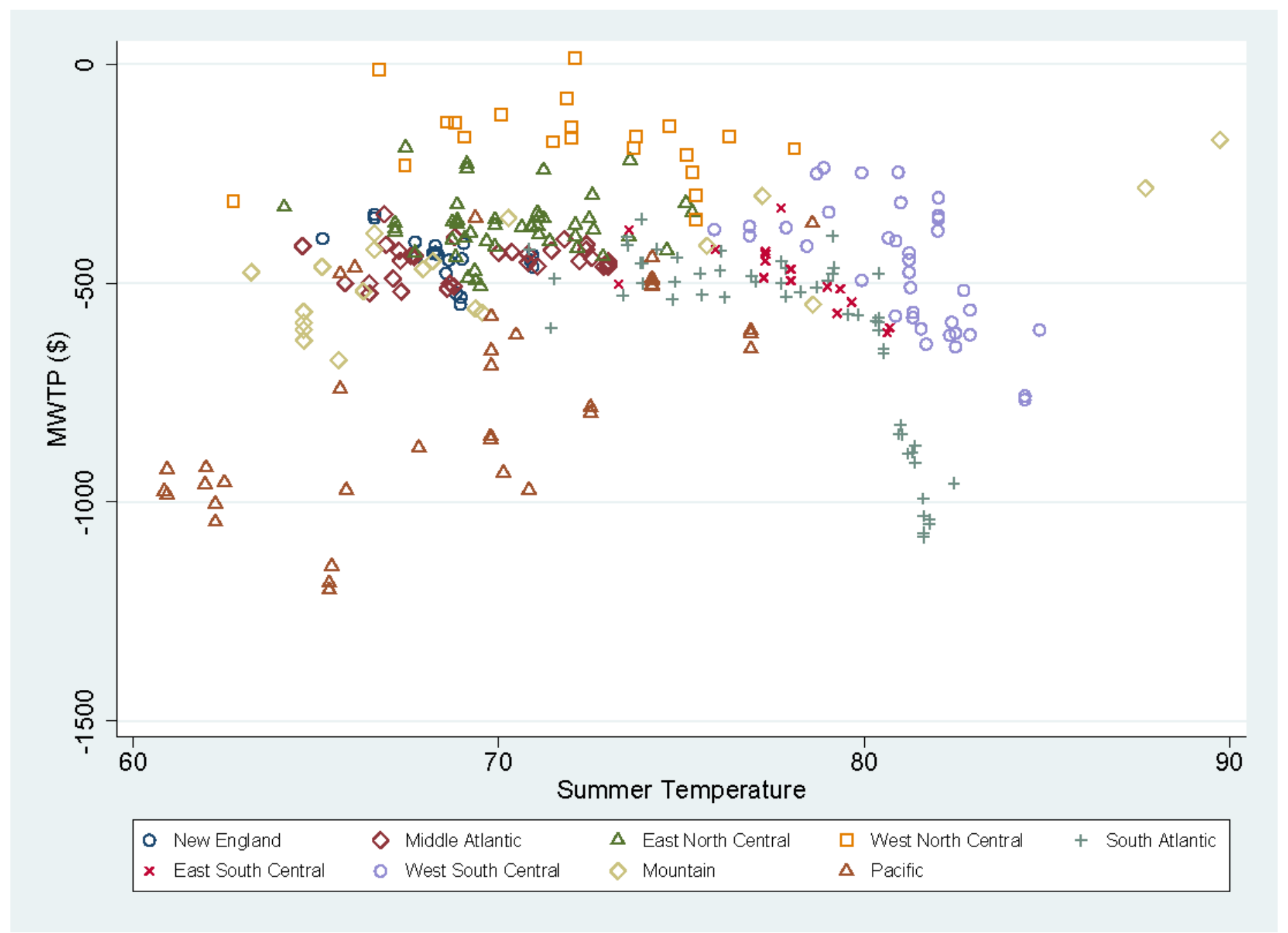


Figure 8. Impact of Removing Moving Costs on Marginal Willingness to Pay for Temperature by Metropolitan Area, With Tax Adjustments (Models M.2 and M.3)

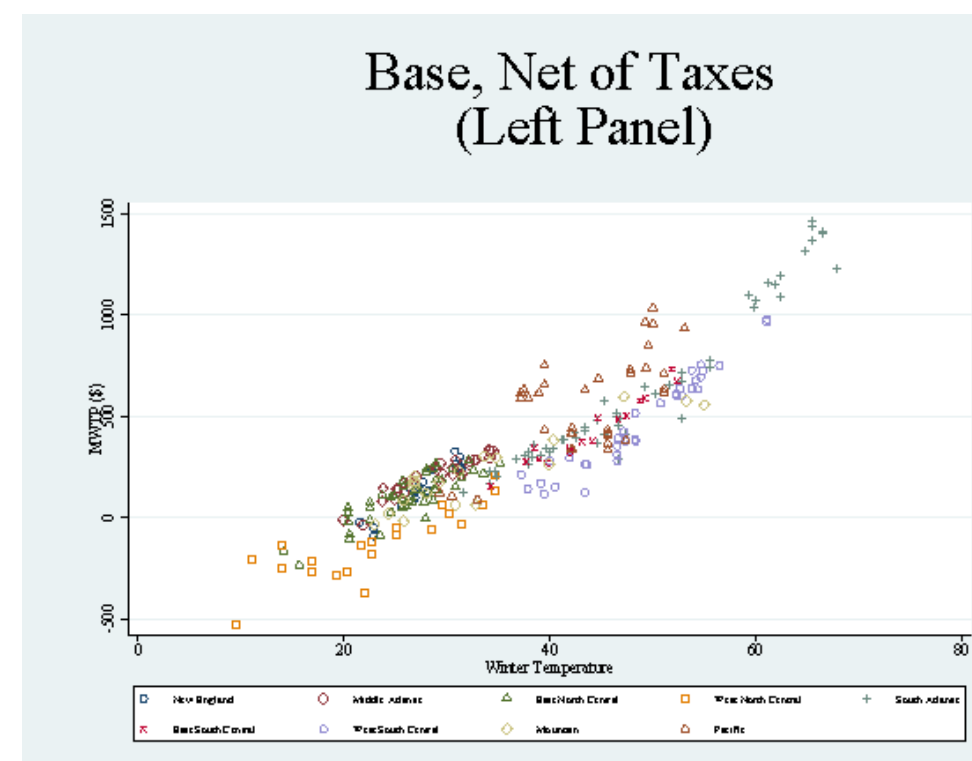
Omit Moving Costs, Net of Taxes (Right Panel)
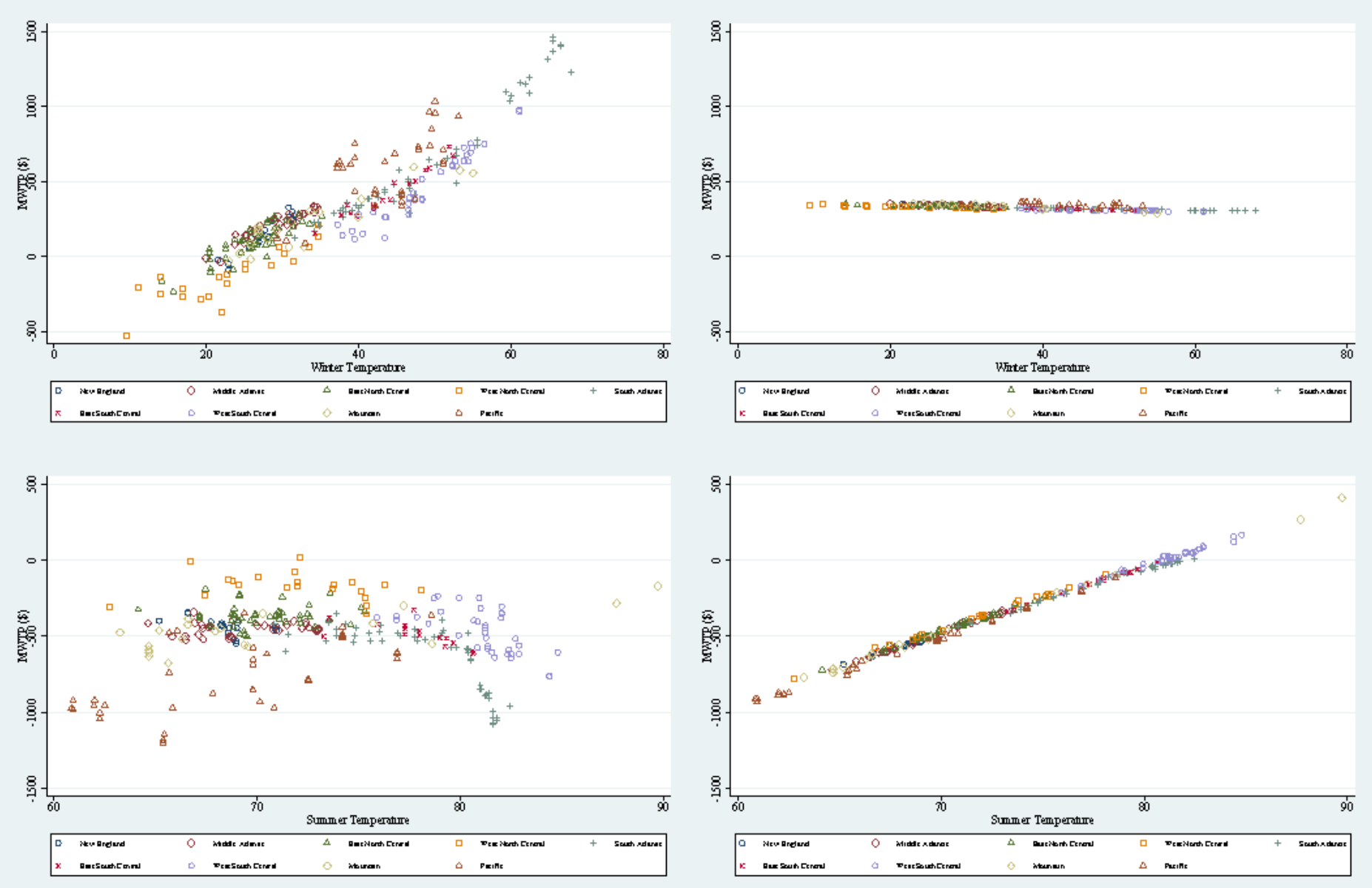


\section{Appendix}

Table A.1. Summary of Hedonic Wage Coefficients

\begin{tabular}{|c|c|c|c|}
\hline \multirow[b]{2}{*}{ (Dependent variable: $\log ($ wage rate)) } & \multirow{2}{*}{$\begin{array}{c}\text { National } \\
\text { equation } \\
\text { Coef. }\end{array}$} & \multicolumn{2}{|c|}{$\begin{array}{l}\text { MSA-specific } \\
\text { equations (284) }\end{array}$} \\
\hline & & Mean(Coef.) & Std.dev.(Coef.) \\
\hline High school (left-out category is no high school) & 0.117 & 0.098 & 0.038 \\
\hline Some college & 0.212 & 0.180 & 0.045 \\
\hline College graduate & 0.418 & 0.382 & 0.069 \\
\hline Higher education & 0.577 & 0.546 & 0.074 \\
\hline Age & 0.049 & 0.048 & 0.007 \\
\hline Age squared (divided by 100 ) & 0.000 & 0.000 & 0.000 \\
\hline Married & 0.093 & 0.092 & 0.021 \\
\hline Male & 0.197 & 0.215 & 0.040 \\
\hline Black (left-out category is white) & -0.082 & -0.070 & 0.070 \\
\hline Other race & -0.086 & -0.055 & 0.054 \\
\hline Speaks English well & 0.213 & 0.126 & 0.103 \\
\hline Hispanic & -0.075 & -0.057 & 0.074 \\
\hline $\begin{array}{l}\text { Business operations occupation (left-out category is } \\
\text { management occupation) }\end{array}$ & -0.120 & -0.122 & 0.067 \\
\hline Financial specialists occupation & -0.139 & -0.116 & 0.072 \\
\hline Computer and math occupation & 0.010 & 0.004 & 0.089 \\
\hline Engineering occupation & -0.088 & -0.073 & 0.083 \\
\hline Life, physical, and social sciences occupation & -0.206 & -0.180 & 0.100 \\
\hline Social services occupation & -0.354 & -0.328 & 0.078 \\
\hline Legal occupation & -0.023 & -0.039 & 0.127 \\
\hline Teachers occupation & -0.221 & -0.190 & 0.093 \\
\hline Other educational occupation & -0.502 & -0.473 & 0.129 \\
\hline Arts, sports, and media occupation & -0.220 & -0.243 & 0.094 \\
\hline Healthcare practitioners occupation & 0.025 & 0.062 & 0.078 \\
\hline Healthcare support occupation & -0.351 & -0.330 & 0.078 \\
\hline Protective services occupation & -0.257 & -0.240 & 0.106 \\
\hline Food and serving occupation & -0.453 & -0.428 & 0.077 \\
\hline Maintenance occupation & -0.485 & -0.472 & 0.074 \\
\hline Personal care service occupation & -0.435 & -0.423 & 0.114 \\
\hline High-skill sales occupation & -0.154 & -0.136 & 0.067 \\
\hline Low-skill sales occupation & -0.227 & -0.228 & 0.062 \\
\hline Office support occupation & -0.316 & -0.298 & 0.049 \\
\hline $\begin{array}{l}\text { Construction trades and extraction workers } \\
\text { occupation }\end{array}$ & -0.248 & -0.246 & 0.090 \\
\hline Maintenance workers occupation & -0.206 & -0.192 & 0.065 \\
\hline Production occupation & -0.346 & -0.317 & 0.084 \\
\hline Transportation occupation & -0.375 & -0.357 & 0.075 \\
\hline $\begin{array}{l}\text { Construction industry (left-out category is mining } \\
\text { and utilities) }{ }^{a}\end{array}$ & -0.179 & -0.180 & 0.095 \\
\hline Manufacturing industry & -0.127 & -0.120 & 0.107 \\
\hline
\end{tabular}




\begin{tabular}{|c|c|c|c|}
\hline \multirow[b]{2}{*}{ (Dependent variable: log(wage rate)) } & \multirow{2}{*}{$\begin{array}{c}\text { National } \\
\text { equation }\end{array}$} & \multicolumn{2}{|c|}{$\begin{array}{l}\text { MSA-specific } \\
\text { equations (284) }\end{array}$} \\
\hline & & Mean(Coef.) & Std.dev.(Coef.) \\
\hline Wholesale industry & -0.190 & -0.185 & 0.097 \\
\hline Retail industry & -0.344 & -0.339 & 0.094 \\
\hline Transportation industry & -0.111 & -0.084 & 0.107 \\
\hline Information and communications industry & -0.111 & -0.134 & 0.109 \\
\hline Finance industry & -0.151 & -0.175 & 0.105 \\
\hline $\begin{array}{l}\text { Professional and scientific management services } \\
\text { industry }\end{array}$ & -0.197 & -0.220 & 0.101 \\
\hline Educational and health social services industry & -0.280 & -0.267 & 0.092 \\
\hline Recreation and food services industry & -0.352 & -0.370 & 0.110 \\
\hline Other services industry & -0.348 & -0.343 & 0.101 \\
\hline Public administration industry & -0.123 & -0.126 & 0.095 \\
\hline No. of obs. ${ }^{b}$ & $2,916,211$ & 10,268 & 16,223 \\
\hline $\boldsymbol{R}$-squared ${ }^{b}$ & 0.41 & 0.40 & 0.03 \\
\hline
\end{tabular}

${ }^{a}$ Since these two industries have a very low number of observations, we bundled them together as the omitted category.

${ }^{b}$ For the MSA-specific regressions, the value in the first column presents the average number of observations and average $R$-squared value across the 284 MSA regressions, while the second column presents the standard deviation of the relevant statistic across those regressions. 
Table A.2. Summary of Hedonic Housing Coefficients

\begin{tabular}{|c|c|c|c|}
\hline \multirow[b]{2}{*}{$\begin{array}{l}\text { (Dependent variable: } \log (\text { user costs including } \\
\text { insurance and utility costs)) }\end{array}$} & \multirow{2}{*}{$\begin{array}{c}\text { National } \\
\text { equation } \\
\text { Coef. }\end{array}$} & \multicolumn{2}{|c|}{ MSA-specific equations (284) } \\
\hline & & Mean(Coef.) & Std.dev.(Coef.) \\
\hline House is owned & 0.504 & 0.464 & 0.144 \\
\hline $\begin{array}{l}3 \text { bedrooms (left-out category is less than } 3 \\
\text { bedrooms) }\end{array}$ & 0.128 & 0.160 & 0.061 \\
\hline 4 bedrooms & 0.152 & 0.208 & 0.082 \\
\hline 5 bedrooms & 0.283 & 0.324 & 0.110 \\
\hline Greater than 5 bedrooms & 0.485 & 0.500 & 0.163 \\
\hline $\begin{array}{l}2 \text { rooms (left-out category is less than } 2 \\
\text { rooms) }\end{array}$ & 0.137 & 0.080 & 0.133 \\
\hline 3 rooms & 0.137 & 0.053 & 0.140 \\
\hline 4 rooms & 0.166 & 0.075 & 0.146 \\
\hline 5 rooms & 0.230 & 0.126 & 0.154 \\
\hline 6 rooms & 0.327 & 0.218 & 0.156 \\
\hline Greater than 6 rooms & 0.531 & 0.413 & 0.176 \\
\hline Complete kitchen & -0.033 & -0.104 & 0.261 \\
\hline Complete plumbing & 0.219 & 0.221 & 0.212 \\
\hline 1 to 10 acres & 0.214 & 0.246 & 0.140 \\
\hline 0 to 1 years old & 0.391 & 0.428 & 0.157 \\
\hline 2 to 5 years old & 0.371 & 0.404 & 0.158 \\
\hline 6 to 10 years old & 0.316 & 0.358 & 0.150 \\
\hline 11 to 20 years old & 0.218 & 0.247 & 0.127 \\
\hline 21 to 30 years old & 0.110 & 0.150 & 0.122 \\
\hline 31 to 40 years old & 0.059 & 0.093 & 0.113 \\
\hline 41 to 50 years old & 0.020 & 0.039 & 0.089 \\
\hline $\begin{array}{l}51 \text { to } 60 \text { years old (left-out category is over } 61 \\
\text { years old) }\end{array}$ & -0.026 & -0.011 & 0.075 \\
\hline $\begin{array}{l}\text { Number of units in structure: single-attached } \\
\text { (left-out category is single family detached) }\end{array}$ & -0.158 & -0.082 & 0.105 \\
\hline 2 units in structure & -0.055 & -0.089 & 0.107 \\
\hline 3 to 4 units in structure & -0.112 & -0.135 & 0.095 \\
\hline 5 to 9 units in structure & -0.139 & -0.167 & 0.106 \\
\hline 10 to 19 units in structure & -0.114 & -0.132 & 0.127 \\
\hline 20 to 49 units in structure & -0.169 & -0.154 & 0.151 \\
\hline Over 50 units in structure & -0.152 & -0.190 & 0.207 \\
\hline No. of obs. ${ }^{a}$ & $3,255,748$ & 11,464 & 18,376 \\
\hline $\boldsymbol{R}$-squared ${ }^{a}$ & 0.57 & 0.54 & 0.07 \\
\hline
\end{tabular}

${ }^{a}$ For the MSA-specific regressions, the value in the first column presents the average number of observations and average $R$-squared value across the 284 MSA regressions, while the second column presents the standard deviation of the relevant statistic across those regressions. 
Table A.3. Hedonic Wage, Housing Cost, and Quality of Life Regressions (all coefficients)

\begin{tabular}{|c|c|c|c|c|}
\hline & Wage reg. & Housing cost reg. & $\begin{array}{c}\text { QOL reg. } \\
\text { traditional weights }\end{array}$ & $\begin{array}{c}\text { QOL reg. } \\
\text { adjusted weights }\end{array}$ \\
\hline Variable & $\begin{array}{c}\text { Coef. } \\
\text { (Std. err.) }\end{array}$ & $\begin{array}{c}\text { Coef. } \\
\text { (Std. err.) }\end{array}$ & $\begin{array}{c}\text { Coef. } \\
\text { (Std. err.) }\end{array}$ & $\begin{array}{c}\text { Coef. } \\
\text { (Std. err.) }\end{array}$ \\
\hline Avg. winter temperature & $\begin{array}{l}-0.0030 \\
(0.0008)\end{array}$ & $\begin{array}{l}-0.0001 \\
(0.0020)\end{array}$ & $\begin{array}{c}0.0030 \\
(0.0006)\end{array}$ & $\begin{array}{c}0.0015 \\
(0.0005)\end{array}$ \\
\hline Avg. summer temperature & $\begin{array}{l}-0.0010 \\
(0.0015)\end{array}$ & $\begin{array}{l}-0.0172 \\
(0.0040)\end{array}$ & $\begin{array}{l}-0.0033 \\
(0.0010)\end{array}$ & $\begin{array}{l}-0.0052 \\
(0.0009)\end{array}$ \\
\hline July humidity & $\begin{array}{l}-0.0007 \\
(0.0007)\end{array}$ & $\begin{array}{c}0.0020 \\
(0.0016)\end{array}$ & $\begin{array}{c}0.0012 \\
(0.0005)\end{array}$ & $\begin{array}{c}0.0010 \\
(0.0003)\end{array}$ \\
\hline Annual snowfall & $\begin{array}{l}-0.0010 \\
(0.0003)\end{array}$ & $\begin{array}{l}-0.0022 \\
(0.0007)\end{array}$ & $\begin{array}{c}0.0004 \\
(0.0002)\end{array}$ & $\begin{array}{l}-0.0002 \\
(0.0002)\end{array}$ \\
\hline Ln(summer precipitation) & $\begin{array}{l}-0.0247 \\
(0.0111)\end{array}$ & $\begin{array}{l}-0.0475 \\
(0.0283)\end{array}$ & $\begin{array}{c}0.0128 \\
(0.0080)\end{array}$ & $\begin{array}{l}-0.0031 \\
(0.0067)\end{array}$ \\
\hline Annual sunshine & $\begin{array}{c}0.0004 \\
(0.0009)\end{array}$ & $\begin{array}{c}0.0089 \\
(0.0022)\end{array}$ & $\begin{array}{c}0.0019 \\
(0.0006)\end{array}$ & $\begin{array}{c}0.0028 \\
(0.0005)\end{array}$ \\
\hline Ln(population density) & $\begin{array}{c}0.0504 \\
(0.0069)\end{array}$ & $\begin{array}{c}0.1302 \\
(0.0168)\end{array}$ & $\begin{array}{l}-0.0179 \\
(0.0049)\end{array}$ & $\begin{array}{c}0.0173 \\
(0.0039)\end{array}$ \\
\hline Mean $\mathrm{PM}_{2.5}$ & $\begin{array}{c}0.0036 \\
(0.0018)\end{array}$ & $\begin{array}{l}-0.0076 \\
(0.0042)\end{array}$ & $\begin{array}{l}-0.0056 \\
(0.0014)\end{array}$ & $\begin{array}{l}-0.0044 \\
(0.0011)\end{array}$ \\
\hline Violent crime rate & $\begin{array}{c}0.0019 \\
(0.0019)\end{array}$ & $\begin{array}{l}-0.0096 \\
(0.0043)\end{array}$ & $\begin{array}{l}-0.0043 \\
(0.0017)\end{array}$ & $\begin{array}{l}-0.0042 \\
(0.0013)\end{array}$ \\
\hline Transportation score & $\begin{array}{l}-0.0007 \\
(0.0002)\end{array}$ & $\begin{array}{l}-0.0015 \\
(0.0005)\end{array}$ & $\begin{array}{c}0.0003 \\
(0.0001)\end{array}$ & $\begin{array}{l}-0.0001 \\
(0.0001)\end{array}$ \\
\hline Education score & $\begin{array}{c}0.0000 \\
(0.0002)\end{array}$ & $\begin{array}{c}0.0000 \\
(0.0006)\end{array}$ & $\begin{array}{c}0.0000 \\
(0.0001)\end{array}$ & $\begin{array}{c}0.0000 \\
(0.0001)\end{array}$ \\
\hline
\end{tabular}




\begin{tabular}{|c|c|c|c|c|}
\hline & Wage reg. & Housing cost reg. & $\begin{array}{c}\text { QOL reg. } \\
\text { traditional weights }\end{array}$ & $\begin{array}{c}\text { QOL reg. } \\
\text { adjusted weights }\end{array}$ \\
\hline Variable & $\begin{array}{c}\text { Coef. } \\
\text { (Std. err.) }\end{array}$ & $\begin{array}{c}\text { Coef. } \\
\text { (Std. err.) }\end{array}$ & $\begin{array}{c}\text { Coef. } \\
\text { (Std. err.) }\end{array}$ & $\begin{array}{c}\text { Coef. } \\
\text { (Std. err.) }\end{array}$ \\
\hline Arts score & $\begin{array}{c}0.0007 \\
(0.0003)\end{array}$ & $\begin{array}{c}0.0013 \\
(0.0006)\end{array}$ & $\begin{array}{l}-0.0004 \\
(0.0002)\end{array}$ & $\begin{array}{c}0.0001 \\
(0.0001)\end{array}$ \\
\hline Healthcare score & $\begin{array}{c}0.0002 \\
(0.0002)\end{array}$ & $\begin{array}{c}0.0013 \\
(0.0004)\end{array}$ & $\begin{array}{c}0.0002 \\
(0.0001)\end{array}$ & $\begin{array}{c}0.0003 \\
(0.0001)\end{array}$ \\
\hline Recreation score & $\begin{array}{c}0.0005 \\
(0.0002)\end{array}$ & $\begin{array}{c}0.0009 \\
(0.0005)\end{array}$ & $\begin{array}{l}-0.0002 \\
(0.0002)\end{array}$ & $\begin{array}{c}0.0001 \\
(0.0001)\end{array}$ \\
\hline Park area & $\begin{array}{c}0.0000 \\
(0.0000)\end{array}$ & $\begin{array}{c}0.0000 \\
(0.0000)\end{array}$ & $\begin{array}{c}0.0000 \\
(0.0000)\end{array}$ & $\begin{array}{c}0.0000 \\
(0.0000)\end{array}$ \\
\hline Visibility > 10 miles & $\begin{array}{c}0.0016 \\
(0.0004)\end{array}$ & $\begin{array}{c}0.0024 \\
(0.0009)\end{array}$ & $\begin{array}{l}-0.0010 \\
(0.0003)\end{array}$ & $\begin{array}{c}0.0000 \\
(0.0002)\end{array}$ \\
\hline Ln(elevation) & $\begin{array}{l}-0.0019 \\
(0.0056)\end{array}$ & $\begin{array}{c}0.0035 \\
(0.0125)\end{array}$ & $\begin{array}{c}0.0027 \\
(0.0043)\end{array}$ & $\begin{array}{c}0.0021 \\
(0.0032)\end{array}$ \\
\hline Distance to coast & $\begin{array}{l}-0.0006 \\
(0.0001)\end{array}$ & $\begin{array}{l}-0.0011 \\
(0.0002)\end{array}$ & $\begin{array}{c}0.0003 \\
(0.0001)\end{array}$ & $\begin{array}{l}-0.0001 \\
(0.0001)\end{array}$ \\
\hline$($ Distance to coast)^2 & $\begin{array}{c}0.0000 \\
(0.0000)\end{array}$ & $\begin{array}{c}0.0000 \\
(0.0000)\end{array}$ & $\begin{array}{c}0.0000 \\
(0.0000)\end{array}$ & $\begin{array}{c}0.0000 \\
(0.0000)\end{array}$ \\
\hline No. of obs. (MSAs) & 284 & 284 & 284 & 284 \\
\hline Adjusted $R$-squared & 0.71 & 0.74 & 0.50 & 0.59 \\
\hline
\end{tabular}

Note: MWTP is computed at mean household income for the prime-aged sample $(\$ 69,161)$. When entering the regressions nonlinearly, amenity variables are evaluated at population-weighted means in order to compute MWTP. Nonlinear covariates are as follows: population density, summer precipitation, and elevation enter in log form, while distance to the coast enters the model quadratically. 
Table A.4. Coefficients for All Location-Specific Amenities, Semipar Hedonic Models

\begin{tabular}{|c|c|c|c|c|c|c|c|c|}
\hline \multirow{3}{*}{$\begin{array}{l}\text { Temperature specification } \\
\text { Variable }\end{array}$} & \multicolumn{4}{|c|}{ Adjusted hedonic weights } & \multicolumn{4}{|c|}{ Traditional hedonic weights } \\
\hline & \multicolumn{2}{|c|}{ Flexible WT } & \multicolumn{2}{|c|}{ Flexible ST } & \multicolumn{2}{|c|}{ Flexible WT } & \multicolumn{2}{|c|}{ Flexible ST } \\
\hline & Coef. & Std. err. & Coef. & Std. err. & Coef. & Std. err. & Coef. & Std. err. \\
\hline Avg. winter temperature & & & 0.00253 & 0.00056 & & & 0.00253 & 0.00072 \\
\hline Avg. summer temperature & -0.00530 & 0.00092 & & & -0.00342 & 0.00117 & & \\
\hline July humidity & 0.00109 & 0.00040 & 0.00108 & 0.00037 & 0.00095 & 0.00050 & 0.00113 & 0.00048 \\
\hline Annual snowfall & -0.00013 & 0.00022 & -0.00043 & 0.00022 & 0.00066 & 0.00028 & 0.00024 & 0.00029 \\
\hline Ln(summer precipitation) & -0.00247 & 0.00647 & -0.00225 & 0.00619 & 0.01542 & 0.00817 & 0.01139 & 0.00801 \\
\hline Annual sunshine & 0.00276 & 0.00057 & 0.00180 & 0.00059 & 0.00196 & 0.00072 & 0.00098 & 0.00077 \\
\hline Ln(population density) & 0.01487 & 0.00348 & 0.01746 & 0.00331 & -0.01893 & 0.00439 & -0.01714 & 0.00428 \\
\hline Mean $\mathrm{PM}_{2.5}$ & -0.00460 & 0.00125 & -0.00669 & 0.00135 & -0.00544 & 0.00158 & -0.00611 & 0.00174 \\
\hline Violent crime rate & -3.79723 & 1.22557 & -3.60350 & 1.20390 & -4.56958 & 1.54697 & -4.56983 & 1.55848 \\
\hline Transportation score & -0.00016 & 0.00012 & -0.00010 & 0.00011 & 0.00036 & 0.00015 & 0.00034 & 0.00015 \\
\hline Education score & 0.00004 & 0.00011 & 0.00000 & 0.00011 & 0.00002 & 0.00014 & 0.00002 & 0.00015 \\
\hline Arts score & 0.00008 & 0.00013 & 0.00009 & 0.00013 & -0.00035 & 0.00016 & -0.00039 & 0.00016 \\
\hline Healthcare score & 0.00035 & 0.00010 & 0.00033 & 0.00009 & 0.00017 & 0.00012 & 0.00021 & 0.00012 \\
\hline Recreation score & 0.00011 & 0.00012 & 0.00004 & 0.00012 & -0.00025 & 0.00015 & -0.00023 & 0.00015 \\
\hline Park area & 0.00000 & 0.00000 & 0.00000 & 0.00000 & -0.00002 & 0.00001 & -0.00001 & 0.00001 \\
\hline Visibility > 10 miles & 0.00003 & 0.00024 & -0.00009 & 0.00023 & -0.00098 & 0.00030 & -0.00073 & 0.00030 \\
\hline Ln(elevation) & 0.00222 & 0.00302 & 0.00170 & 0.00283 & 0.00036 & 0.00381 & 0.00572 & 0.00367 \\
\hline Distance to coast & -0.00006 & 0.00006 & 0.00001 & 0.00004 & 0.00033 & 0.00007 & 0.00015 & 0.00005 \\
\hline$($ Distance to coast)^ 2 & 0.00000 & 0.00000 & 0.00000 & 0.00000 & 0.00000 & 0.00000 & 0.00000 & 0.00000 \\
\hline No. of obs. (MSAs) & 284 & & 284 & & 284 & & 284 & \\
\hline Adjusted $R$-squared & 0.57 & & 0.54 & & 0.46 & & 0.37 & \\
\hline
\end{tabular}


Table A.5. MWTP for All Location-Specific Amenities, Mixed Logit Models

\begin{tabular}{|c|c|c|c|c|c|c|c|c|}
\hline Panel A: 1st stage estimates & \multicolumn{2}{|c|}{ No tax adjustments } & \multicolumn{2}{|c|}{$\begin{array}{l}\text { With tax } \\
\text { adjustments }\end{array}$} & \multicolumn{2}{|c|}{$\begin{array}{l}\text { No tax adjustments }+ \\
\text { omit moving costs }\end{array}$} & \multicolumn{2}{|c|}{$\begin{array}{c}\text { With tax } \\
\text { adjustments }+ \\
\text { omit moving costs }\end{array}$} \\
\hline Variable & $\begin{array}{l}\text { Coef } \\
\text { (Std. } \\
\text { err.) }\end{array}$ & & $\begin{array}{l}\text { Coef } \\
\text { (Std. } \\
\text { err.) }\end{array}$ & & $\begin{array}{l}\text { Coef } \\
\text { (Std. } \\
\text { err.) }\end{array}$ & & $\begin{array}{l}\text { Coef } \\
\text { (Std. } \\
\text { err.) }\end{array}$ & \\
\hline Std. dev.: avg. winter temperature & $\begin{array}{c}0.0588 \\
(0.0026)\end{array}$ & & $\begin{array}{c}0.0592 \\
(0.0026)\end{array}$ & & $\begin{array}{c}0.0011 \\
(0.0128)\end{array}$ & & $\begin{array}{c}0.0032 \\
(0.0097)\end{array}$ & \\
\hline Std. dev.: avg. summer temperature & $\begin{array}{c}0.0592 \\
(0.0068)\end{array}$ & & $\begin{array}{c}0.0612 \\
(0.0066)\end{array}$ & & $\begin{array}{c}0.0352 \\
(0.0215)\end{array}$ & & $\begin{array}{c}0.0525 \\
(0.0174)\end{array}$ & \\
\hline Correlation coefficient & $\begin{array}{l}-0.6893 \\
(0.0827)\end{array}$ & & $\begin{array}{l}-0.6993 \\
(0.0776)\end{array}$ & & $\begin{array}{c}0.8614 \\
(0.2756)\end{array}$ & & $\begin{array}{l}-0.9433 \\
(0.1297)\end{array}$ & \\
\hline Panel B: 2nd stage estimates & & & & & & & & \\
\hline Variable & $\begin{array}{l}\text { Coef } \\
\text { (Std. } \\
\text { err.) }\end{array}$ & $\begin{array}{l}\text { MWTP } \\
\text { (Std. } \\
\text { err.) }\end{array}$ & $\begin{array}{l}\text { Coef } \\
\text { (Std. } \\
\text { err.) }\end{array}$ & $\begin{array}{l}\text { MWTP } \\
\text { (Std. } \\
\text { err.) }\end{array}$ & $\begin{array}{l}\text { Coef } \\
\text { (Std. } \\
\text { err.) }\end{array}$ & $\begin{array}{l}\text { MWTP } \\
\text { (Std. } \\
\text { err.) } \\
\end{array}$ & $\begin{array}{l}\text { Coef } \\
\text { (Std. } \\
\text { err.) }\end{array}$ & $\begin{array}{l}\text { MWTP } \\
\text { (Std. } \\
\text { err.) }\end{array}$ \\
\hline Mean: avg. winter temperature & $\begin{array}{c}0.0209 \\
(0.0058)\end{array}$ & $\begin{array}{c}\$ 518 \\
(\$ 144)\end{array}$ & $\begin{array}{c}0.0210 \\
(0.0057)\end{array}$ & $\begin{array}{c}\$ 382 \\
(\$ 104)\end{array}$ & $\begin{array}{c}0.0184 \\
(0.0055)\end{array}$ & $\begin{array}{l}\$ 491 \\
(\$ 146)\end{array}$ & $\begin{array}{c}0.0171 \\
(0.0055)\end{array}$ & $\begin{array}{c}\$ 326 \\
(\$ 104)\end{array}$ \\
\hline Mean: avg. summer temperature & $\begin{array}{c}-0.0253 \\
(0.0100)\end{array}$ & $\begin{array}{l}-\$ 627 \\
(\$ 249)\end{array}$ & $\begin{array}{l}-0.0286 \\
(0.0098)\end{array}$ & $\begin{array}{l}-\$ 522 \\
(\$ 180)\end{array}$ & $\begin{array}{l}-0.0145 \\
(0.0108)\end{array}$ & $\begin{array}{l}-\$ 386 \\
(\$ 288)\end{array}$ & $\begin{array}{l}-0.0178 \\
(0.0110)\end{array}$ & $\begin{array}{l}-\$ 339 \\
(\$ 209)\end{array}$ \\
\hline July humidity & $\begin{array}{l}-0.0208 \\
(0.0054)\end{array}$ & $\begin{array}{l}-\$ 514 \\
(\$ 135)\end{array}$ & $\begin{array}{l}-0.0198 \\
(0.0052)\end{array}$ & $\begin{array}{c}-\$ 360 \\
(\$ 95)\end{array}$ & $\begin{array}{l}-0.0165 \\
(0.0046)\end{array}$ & $\begin{array}{l}-\$ 440 \\
(\$ 124)\end{array}$ & $\begin{array}{l}-0.0156 \\
(0.0045)\end{array}$ & $\begin{array}{r}-\$ 296 \\
(\$ 85)\end{array}$ \\
\hline Annual snowfall & $\begin{array}{r}-0.0170 \\
(0.0026)\end{array}$ & $\begin{array}{c}-\$ 422 \\
(\$ 66)\end{array}$ & $\begin{array}{l}-0.0176 \\
(0.0026)\end{array}$ & $\begin{array}{c}-\$ 321 \\
(\$ 49)\end{array}$ & $\begin{array}{l}-0.0047 \\
(0.0025)\end{array}$ & $\begin{array}{c}-\$ 126 \\
(\$ 67)\end{array}$ & $\begin{array}{l}-0.0052 \\
(0.0025)\end{array}$ & $\begin{array}{l}-\$ 99 \\
(\$ 48)\end{array}$ \\
\hline Ln(summer precipitation) & $\begin{array}{c}0.1708 \\
(0.0768)\end{array}$ & $\begin{array}{c}\$ 403 \\
(\$ 181)\end{array}$ & $\begin{array}{c}0.1517 \\
(0.0752)\end{array}$ & $\begin{array}{c}\$ 264 \\
(\$ 131)\end{array}$ & $\begin{array}{c}0.0678 \\
(0.0732)\end{array}$ & $\begin{array}{c}\$ 172 \\
(\$ 186)\end{array}$ & $\begin{array}{c}0.0593 \\
(0.0727)\end{array}$ & $\begin{array}{c}\$ 107 \\
(\$ 132)\end{array}$ \\
\hline Annual sunshine & $\begin{array}{l}-0.0149 \\
(0.0060)\end{array}$ & $\begin{array}{l}-\$ 368 \\
(\$ 149)\end{array}$ & $\begin{array}{l}-0.0125 \\
(0.0059)\end{array}$ & $\begin{array}{l}-\$ 229 \\
(\$ 108)\end{array}$ & $\begin{array}{l}-0.0082 \\
(0.0060)\end{array}$ & $\begin{array}{l}-\$ 219 \\
(\$ 159)\end{array}$ & $\begin{array}{l}-0.0040 \\
(0.0059)\end{array}$ & $\begin{array}{c}-\$ 75 \\
(\$ 111)\end{array}$ \\
\hline Ln(population density) & 0.2094 & $\$ 6$ & 0.2559 & $\$ 5$ & 0.2891 & $\$ 8$ & 0.3361 & $\$ 7$ \\
\hline
\end{tabular}




\begin{tabular}{|c|c|c|c|c|c|c|c|c|}
\hline & $(0.0494)$ & $(\$ 1)$ & $(0.0505)$ & $(\$ 1)$ & $(0.0441)$ & $(\$ 1)$ & $(0.0453)$ & $(\$ 1)$ \\
\hline \multirow[t]{2}{*}{ Mean $\mathrm{PM}_{2.5}$} & 0.0572 & $\$ 1,416$ & 0.0553 & $\$ 1,009$ & 0.0546 & $\$ 1,454$ & 0.0543 & $\$ 1,032$ \\
\hline & $(0.0164)$ & $(\$ 408)$ & $(0.0164)$ & $(\$ 301)$ & (0.0153) & $(\$ 410)$ & (0.0153) & $(\$ 291)$ \\
\hline \multirow[t]{2}{*}{ Violent crime rate } & 0.0006 & $\$ 15$ & -0.0018 & $-\$ 33$ & -0.0117 & $-\$ 312$ & -0.0142 & $-\$ 270$ \\
\hline & $(0.0142)$ & $(\$ 352)$ & $(0.0141)$ & $(\$ 258)$ & $(0.0150)$ & $(\$ 400)$ & $(0.0150)$ & $(\$ 286)$ \\
\hline \multirow[t]{2}{*}{ Transportation score } & 0.0105 & $\$ 259$ & 0.0099 & $\$ 180$ & 0.0112 & $\$ 298$ & 0.0106 & $\$ 202$ \\
\hline & $(0.0015)$ & (\$39) & $(0.0015)$ & $(\$ 28)$ & $(0.0015)$ & $(\$ 41)$ & $(0.0015)$ & $(\$ 29)$ \\
\hline \multirow[t]{2}{*}{ Education score } & 0.0043 & $\$ 106$ & 0.0041 & $\$ 76$ & 0.0035 & $\$ 92$ & 0.0033 & $\$ 63$ \\
\hline & $(0.0016)$ & $(\$ 41)$ & $(0.0016)$ & $(\$ 30)$ & $(0.0016)$ & $(\$ 43)$ & $(0.0016)$ & $(\$ 30)$ \\
\hline \multirow[t]{2}{*}{ Arts score } & 0.0043 & $\$ 106$ & 0.0047 & $\$ 86$ & 0.0034 & $\$ 90$ & 0.0037 & $\$ 71$ \\
\hline & $(0.0018)$ & $(\$ 46)$ & (0.0019) & $(\$ 34)$ & $(0.0016)$ & $(\$ 42)$ & $(0.0016)$ & $(\$ 30)$ \\
\hline \multirow[t]{2}{*}{ Healthcare score } & 0.0002 & $\$ 4$ & 0.0008 & $\$ 14$ & 0.0002 & $\$ 6$ & 0.0008 & $\$ 15$ \\
\hline & $(0.0012)$ & $(\$ 31)$ & $(0.0012)$ & $(\$ 23)$ & $(0.0012)$ & $(\$ 32)$ & $(0.0012)$ & $(\$ 23)$ \\
\hline \multirow[t]{2}{*}{ Recreation score } & 0.0124 & $\$ 307$ & 0.0126 & $\$ 229$ & 0.0120 & $\$ 320$ & 0.0122 & $\$ 232$ \\
\hline & $(0.0016)$ & $(\$ 41)$ & $(0.0016)$ & $(\$ 30)$ & $(0.0016)$ & $(\$ 42)$ & $(0.0016)$ & $(\$ 30)$ \\
\hline \multirow[t]{2}{*}{ Park area } & 0.0001 & $\$ 4$ & 0.0002 & $\$ 3$ & 0.0001 & $\$ 3$ & 0.0001 & $\$ 2$ \\
\hline & $(0.0001)$ & $(\$ 1)$ & $(0.0001)$ & $(\$ 1)$ & $(0.0000)$ & $(\$ 1)$ & $(0.0000)$ & $(\$ 1)$ \\
\hline \multirow[t]{2}{*}{ Visibility > 10 miles } & 0.0073 & $\$ 180$ & 0.0081 & $\$ 147$ & 0.0009 & $\$ 24$ & 0.0011 & $\$ 22$ \\
\hline & $(0.0033)$ & $(\$ 82)$ & $(0.0033)$ & $(\$ 61)$ & $(0.0035)$ & $(\$ 92)$ & $(0.0035)$ & $(\$ 66)$ \\
\hline \multirow[t]{2}{*}{ Ln(elevation) } & 0.0895 & $\$ 12,450$ & 0.0935 & $\$ 9,578$ & 0.1145 & $\$ 17,142$ & 0.1166 & $\$ 12,454$ \\
\hline & $(0.0481)$ & $(\$ 6,706)$ & $(0.0477)$ & $(\$ 4,891)$ & $(0.0415)$ & $(\$ 6,234)$ & $(0.0411)$ & $(\$ 4,404)$ \\
\hline \multirow[t]{2}{*}{ Distance to coast } & -0.0020 & $-\$ 25$ & -0.0023 & $-\$ 25$ & -0.0012 & $-\$ 19$ & -0.0014 & $-\$ 18$ \\
\hline & $(0.0007)$ & $(\$ 14)$ & $(0.0007)$ & $(\$ 10)$ & $(0.0008)$ & $(\$ 15)$ & $(0.0008)$ & $(\$ 11)$ \\
\hline \multirow[t]{2}{*}{$($ Distance to coast)^ 2} & 0.0000 & & 0.0000 & & 0.0000 & & 0.0000 & \\
\hline & $(0.0000)$ & & $(0.0000)$ & & $(0.0000)$ & & $(0.0000)$ & \\
\hline No. of obs. (MSAs) & 284 & & 284 & & 284 & & 284 & \\
\hline Adjusted $R$-squared & 0.82 & & 0.83 & & 0.82 & & 0.83 & \\
\hline
\end{tabular}

Note: When entering the regressions nonlinearly, amenity variables are evaluated at population-weighted means in order to compute MWTP. Nonlinear covariates are as follows: population density, summer precipitation, and elevation enter in log form, while distance to the coast enters the model quadratically. 
Table A.6. MWTP for Climate Amenities, Mixed Logit Models (sensitivity to specification of utility function)

\begin{tabular}{|c|c|c|c|c|c|c|}
\hline $\begin{array}{l}\text { Panel A: 1st stage } \\
\text { estimates }\end{array}$ & \multicolumn{2}{|c|}{$\begin{array}{l}\text { Jo tax } \\
\text { stments }\end{array}$} & \multicolumn{2}{|l|}{$\begin{array}{l}\text { Quadratic } \\
\text { Hicksian } \\
\text { bundle }\end{array}$} & \multicolumn{2}{|c|}{$\begin{array}{l}\text { Cobb-Douglas utility } \\
\text { Log(wage) in 1st stage with } \\
\text { housing price index in } 2 \text { nd stage }\end{array}$} \\
\hline Variable & $\begin{array}{l}\text { Coef } \\
\text { (Std. } \\
\text { err.) }\end{array}$ & & $\begin{array}{l}\text { Coef } \\
\text { (Std. } \\
\text { err.) }\end{array}$ & & $\begin{array}{l}\text { Coef } \\
\text { (Std. } \\
\text { err.) }\end{array}$ & \\
\hline $\begin{array}{l}\text { Std. dev.: avg. winter } \\
\text { temperature }\end{array}$ & $\begin{array}{l}0.0588 \\
(0.0026)\end{array}$ & & $\begin{array}{l}0.0584 \\
(0.0026)\end{array}$ & & $\begin{array}{l}0.0603 \\
(0.0025)\end{array}$ & \\
\hline $\begin{array}{l}\text { Std. dev.: avg. summer } \\
\text { temperature }\end{array}$ & $\begin{array}{l}0.0592 \\
(0.0068)\end{array}$ & & $\begin{array}{l}0.0572 \\
(0.0069)\end{array}$ & & $\begin{array}{l}0.0555 \\
(0.0070)\end{array}$ & \\
\hline Correlation coefficient & $\begin{array}{l}-0.6893 \\
(0.0827)\end{array}$ & & $\begin{array}{l}-0.7007 \\
(0.0863)\end{array}$ & & $\begin{array}{l}-0.7624 \\
(0.0851)\end{array}$ & \\
\hline $\begin{array}{l}\text { Panel B: 2nd stage } \\
\text { estimates }\end{array}$ & & & & & & \\
\hline Variable & $\begin{array}{l}\text { Coef } \\
\text { (Std. } \\
\text { err.) }\end{array}$ & $\begin{array}{l}\text { MWTP } \\
\text { (Std. } \\
\text { err.) }\end{array}$ & $\begin{array}{l}\text { Coef } \\
\text { (Std. } \\
\text { err.) }\end{array}$ & $\begin{array}{l}\text { MWTP } \\
\text { (Std. } \\
\text { err.) }\end{array}$ & $\begin{array}{l}\text { Coef } \\
\text { (Std. } \\
\text { err.) }\end{array}$ & $\begin{array}{l}\text { MWTP } \\
\text { (Std. err.) }\end{array}$ \\
\hline $\begin{array}{l}\text { Mean: avg. winter } \\
\text { temperature }\end{array}$ & $\begin{array}{l}0.0209 \\
(0.0058)\end{array}$ & $\begin{array}{l}\$ 518 \\
(\$ 144)\end{array}$ & $\begin{array}{l}0.0218 \\
(0.0058)\end{array}$ & $\begin{array}{l}\$ 463 \\
(\$ 126)\end{array}$ & $\begin{array}{l}0.0190 \\
(0.0059)\end{array}$ & $\begin{array}{l}\$ 590 \\
(\$ 184)\end{array}$ \\
\hline $\begin{array}{l}\text { Mean: avg. summer } \\
\text { temperature }\end{array}$ & $\begin{array}{l}-0.0253 \\
(0.0100)\end{array}$ & $\begin{array}{l}-\$ 627 \\
(\$ 249)\end{array}$ & $\begin{array}{l}-0.0266 \\
(0.0099)\end{array}$ & $\begin{array}{l}-\$ 566 \\
(\$ 214)\end{array}$ & $\begin{array}{l}-0.0208 \\
(0.0102)\end{array}$ & $\begin{array}{l}-\$ 644 \\
(\$ 317)\end{array}$ \\
\hline
\end{tabular}

Note: All models are estimated using income before taxes. 
Figure A.1. Marginal Willingness to Pay for Winter Temperature by Metropolitan Area, Local Linear Hedonic Model, Adjusted Weights (various bandwidths)
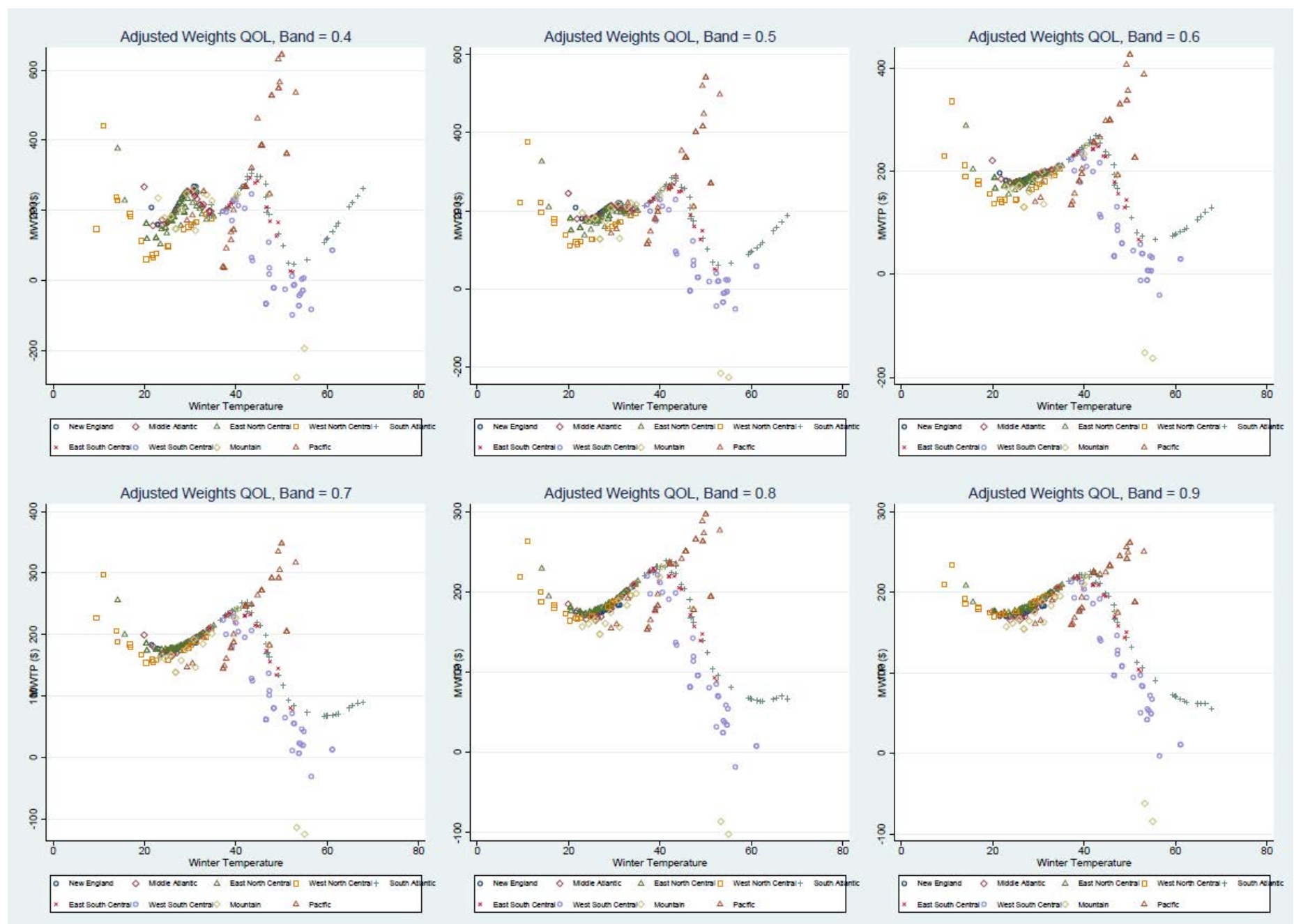
Figure A.2. Marginal Willingness to Pay for Summer Temperature by Metropolitan Area, Local Linear Hedonic Model, Adjusted Weights (various bandwidths)
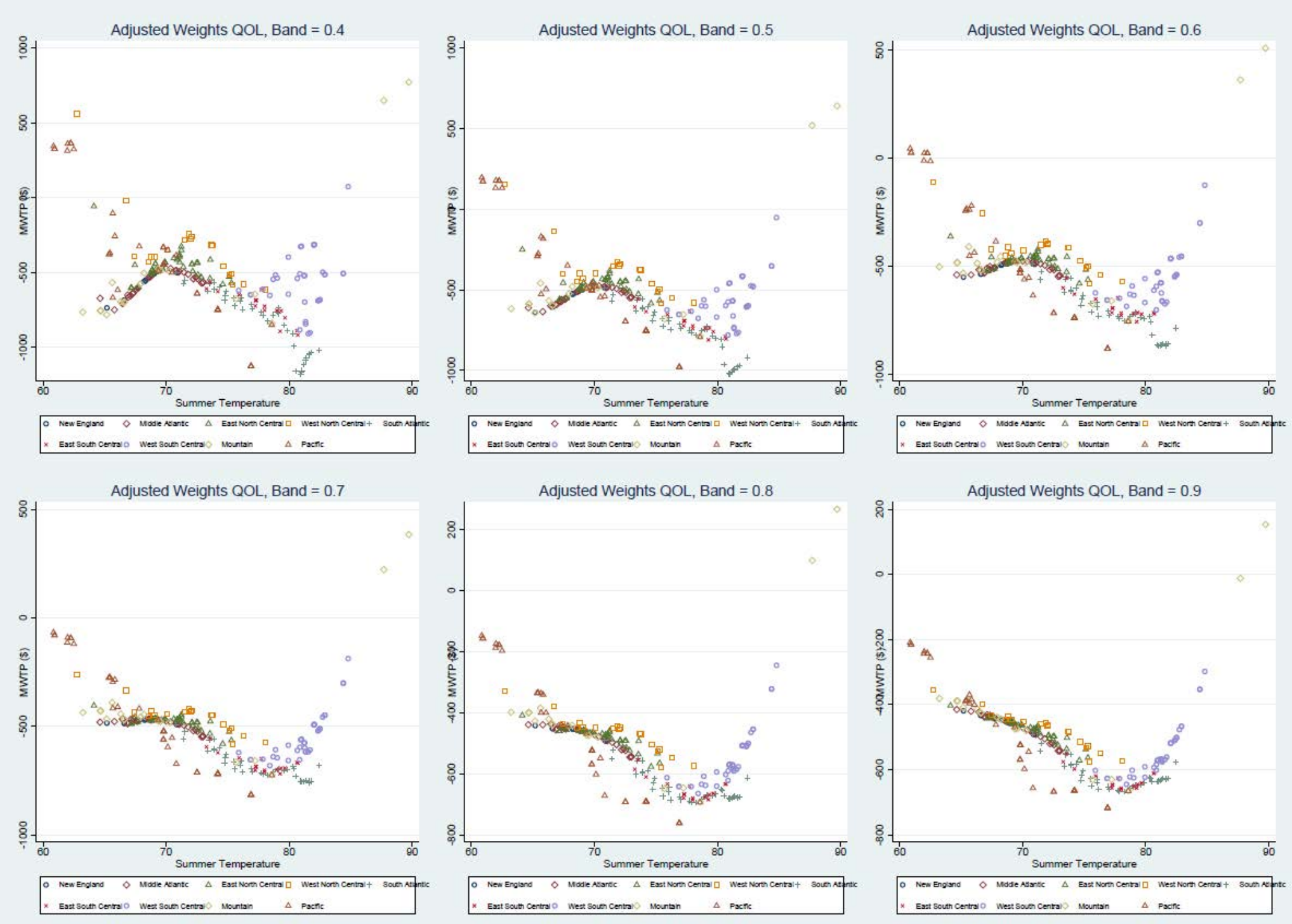
Figure A.3. Marginal Willingness to Pay for Winter Temperature by Metropolitan Area, Local Linear Hedonic Model, Traditional Weights (various bandwidths)
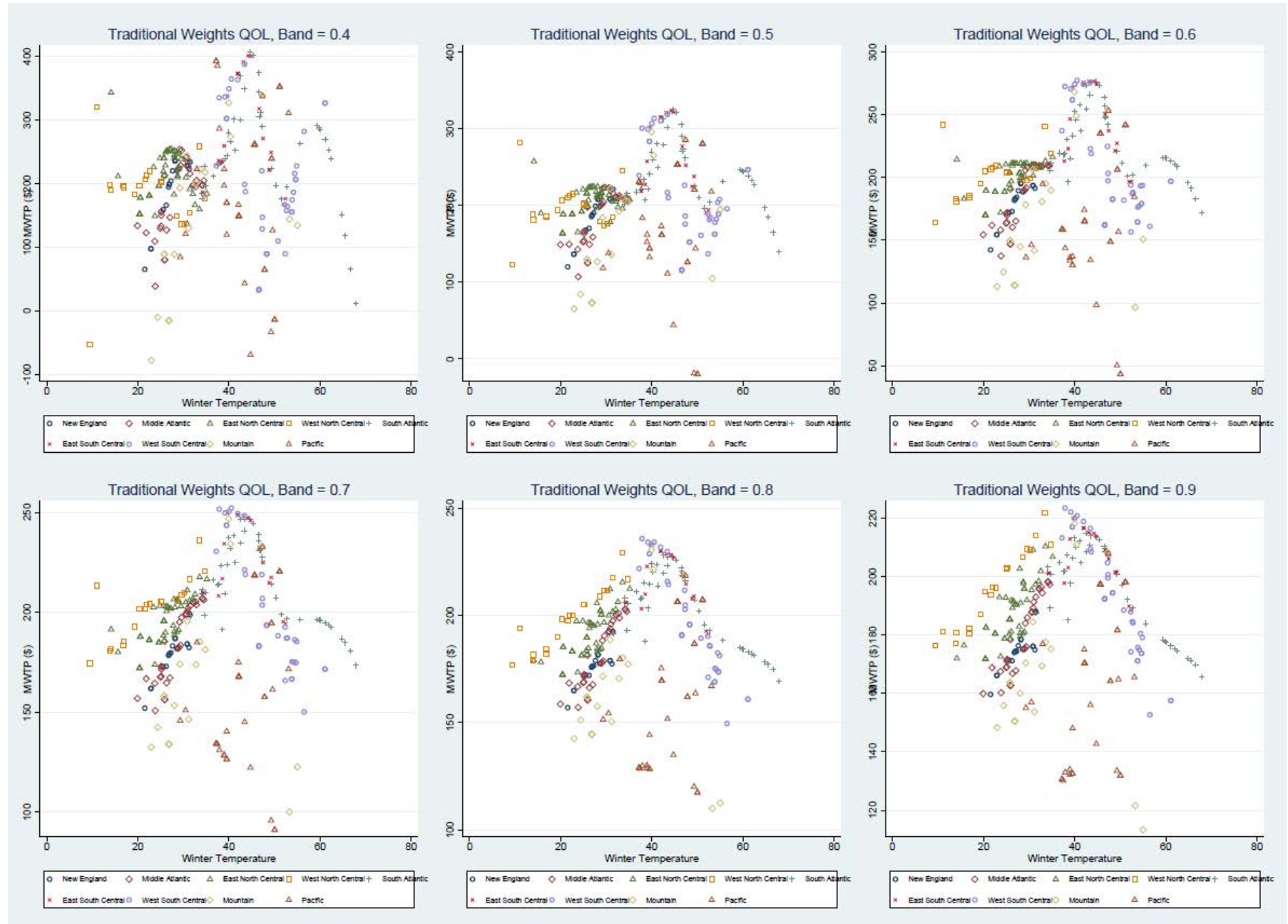
Figure A.4. Marginal Willingness to Pay for Summer Temperature by Metropolitan Area, Local Linear Hedonic Model, Traditional Weights (various bandwidths)
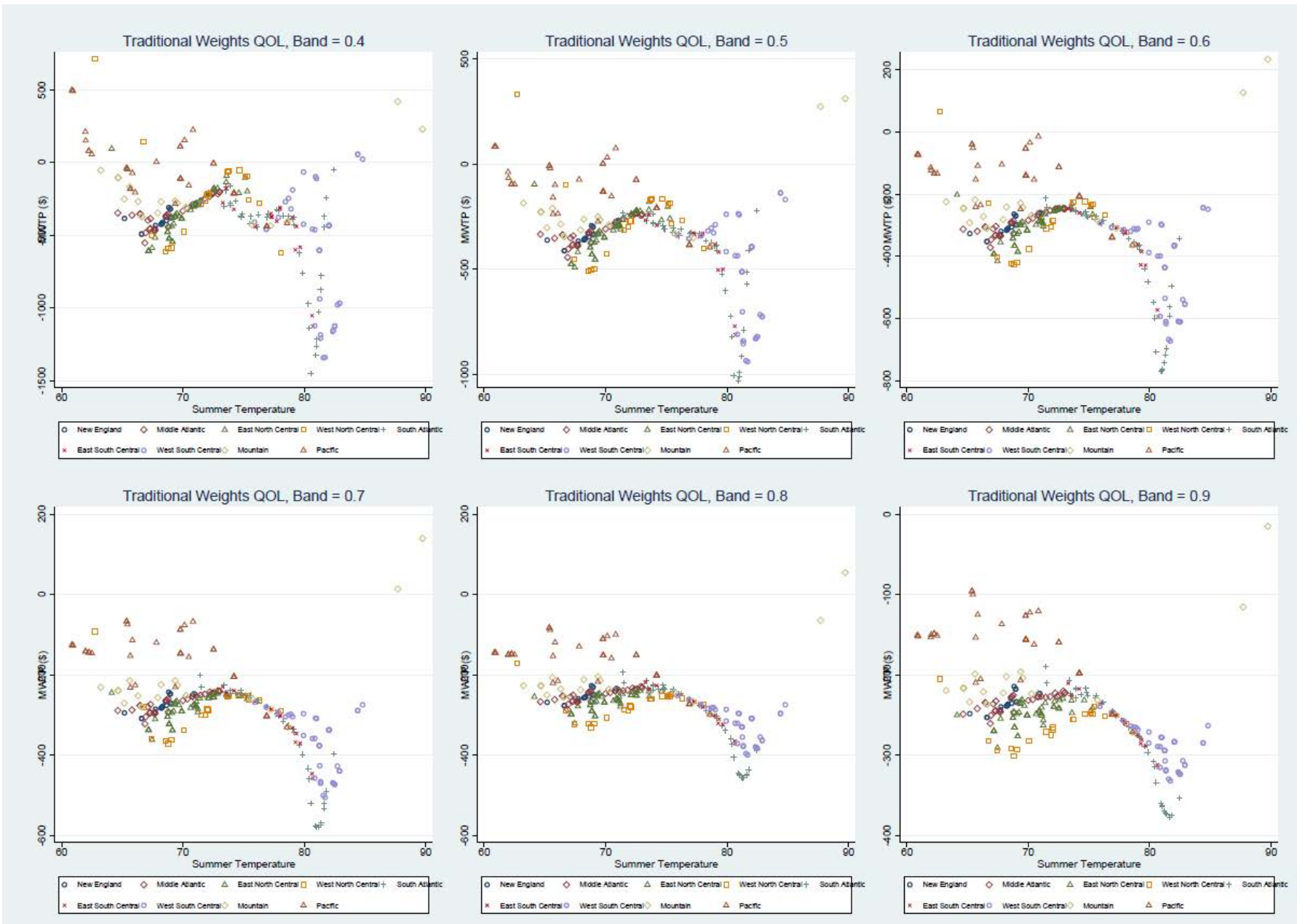